\title{
Formation and Reactivity of New Isoporphyrins: Implications for Understanding the Tyr-His Cross-Link Cofactor Biogenesis in Cytochrome $c$ Oxidase
}

Melanie A. Ehudin, ${ }^{\dagger}$ Laura Senft, ${ }^{\ddagger}$ Alicja Franke, ${ }^{\ddagger}$ Ivana Ivanović-Burmazović, ${ }^{\ddagger}$ and Kenneth D. Karlin ${ }^{\star}, \dagger$

${ }^{\dagger}$ Department of Chemistry, Johns Hopkins University, Baltimore, Maryland 21218, United States

${ }^{\ddagger}$ Department of Chemistry and Pharmacy, Friedrich-Alexander University Erlangen-Nuremberg, 91058 Erlangen, Germany.

\section{Table of Contents:}

I. Iron(III) meso-X-isoporphyrins.

II. Cryo-ESI-MS $\left(-90^{\circ} \mathrm{C}\right)$ and UV-vis $\left(-90^{\circ} \mathrm{C}\right)$ \& EPR $(10 \mathrm{~K})$ spectroscopies following the formation of novel iron(III) meso-X-isoporphyrin complexes (where $\mathrm{X}=$ chloro, azide, cyanide, or 4,5-dimethylimidazole).

III. ${ }^{2} \mathrm{H}-\mathrm{NMR}$ spectroscopy at $-90^{\circ} \mathrm{C}$ following the formation of novel iron(III) meso$\mathrm{X}$-isoporphyrin complexes (where $\mathrm{X}=$ azide or cyanide).

IV. Cryo-ESI-MS and UV-vis $\left(-90^{\circ} \mathrm{C}\right),{ }^{2} \mathrm{H}-\mathrm{NMR}\left(-90^{\circ} \mathrm{C}\right)$, \& EPR $(10 \mathrm{~K})$ spectroscopies following the reactivity of the iron(III) meso-4,5-dimethylimidazole-isoporphyrin complex.

VI. References 


\section{Iron(III) meso-X-isoporphyrins.}

(A)

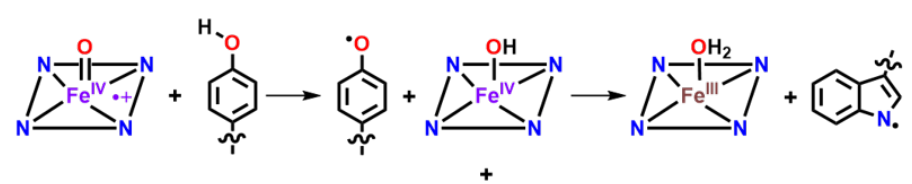

(B)

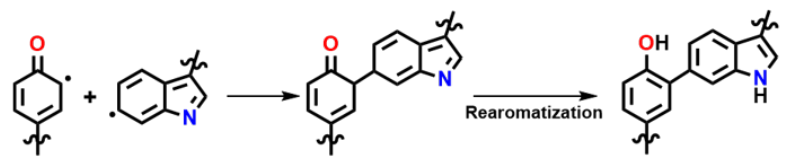

(C)

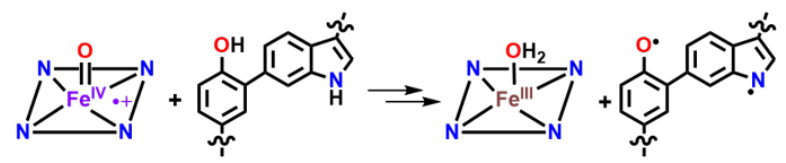

(D)

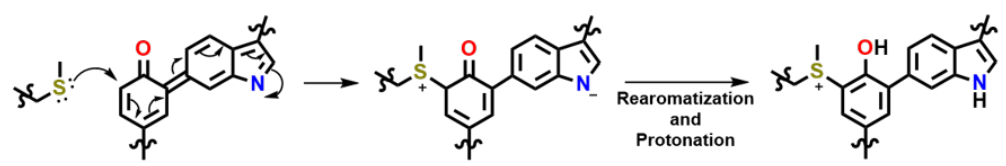

(E)
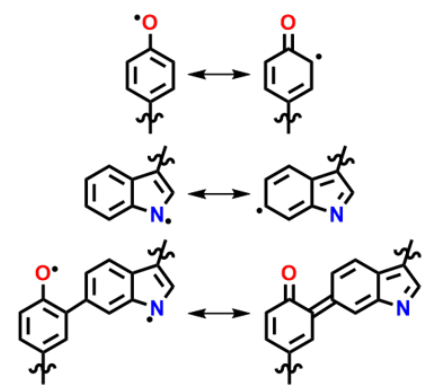

(F)

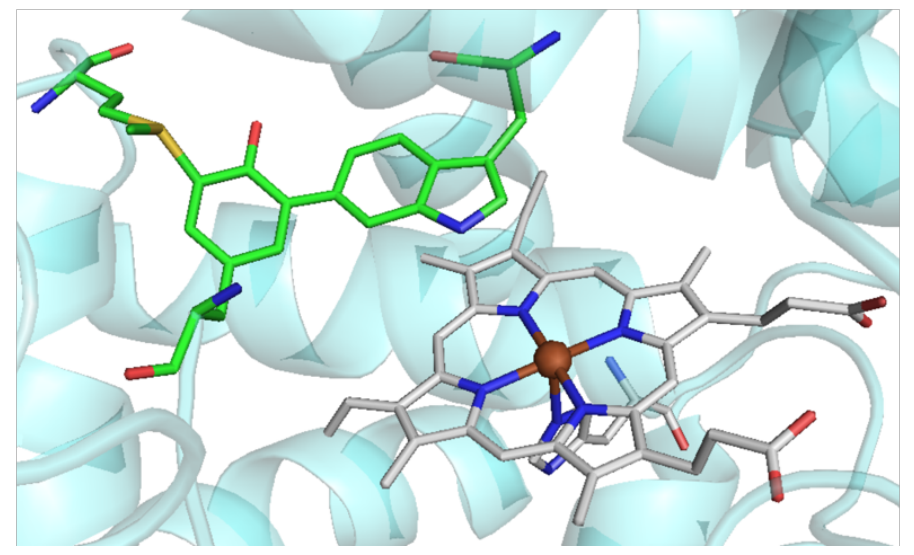

Scheme S1. Proposed pathway behind Met-Tyr-Trp cofactor biogenesis in KatG enzymes (A-E) and active site structure of $M$. tuberculosis KatG showing Met-Tyr-Trp cross-link and heme cofactor (F, PDB: 1SJ2). ${ }^{1-5}$ Part $\mathbf{F}$ was generated using PyMOL (www.pymol.org). ${ }^{6}$ 
(A)

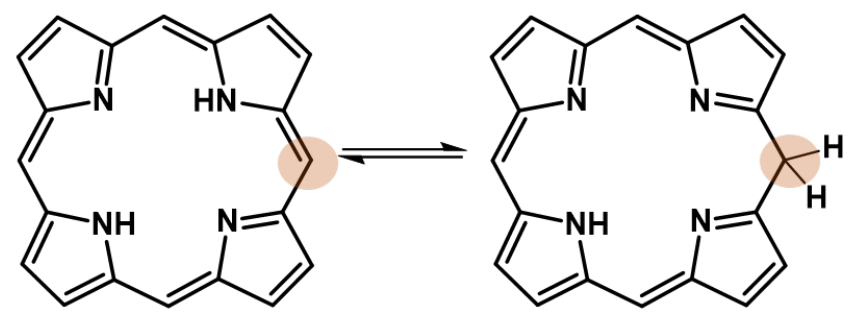

(B)

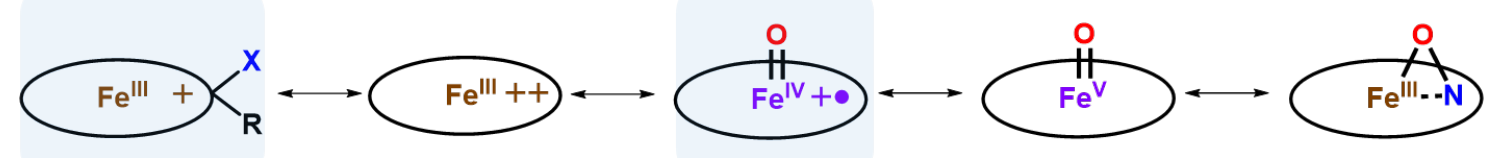

Figure S1. NH-tautomerization between porphyrin (left) and isoporphyrin (right) macrocycles (A). Iron(III) meso-isoporphyrin complexes are isoelectronic with iron(IV) oxo $\pi$-cation radical complexes $(\mathrm{Cmpd}-\mathrm{I})(\mathbf{B})$. 


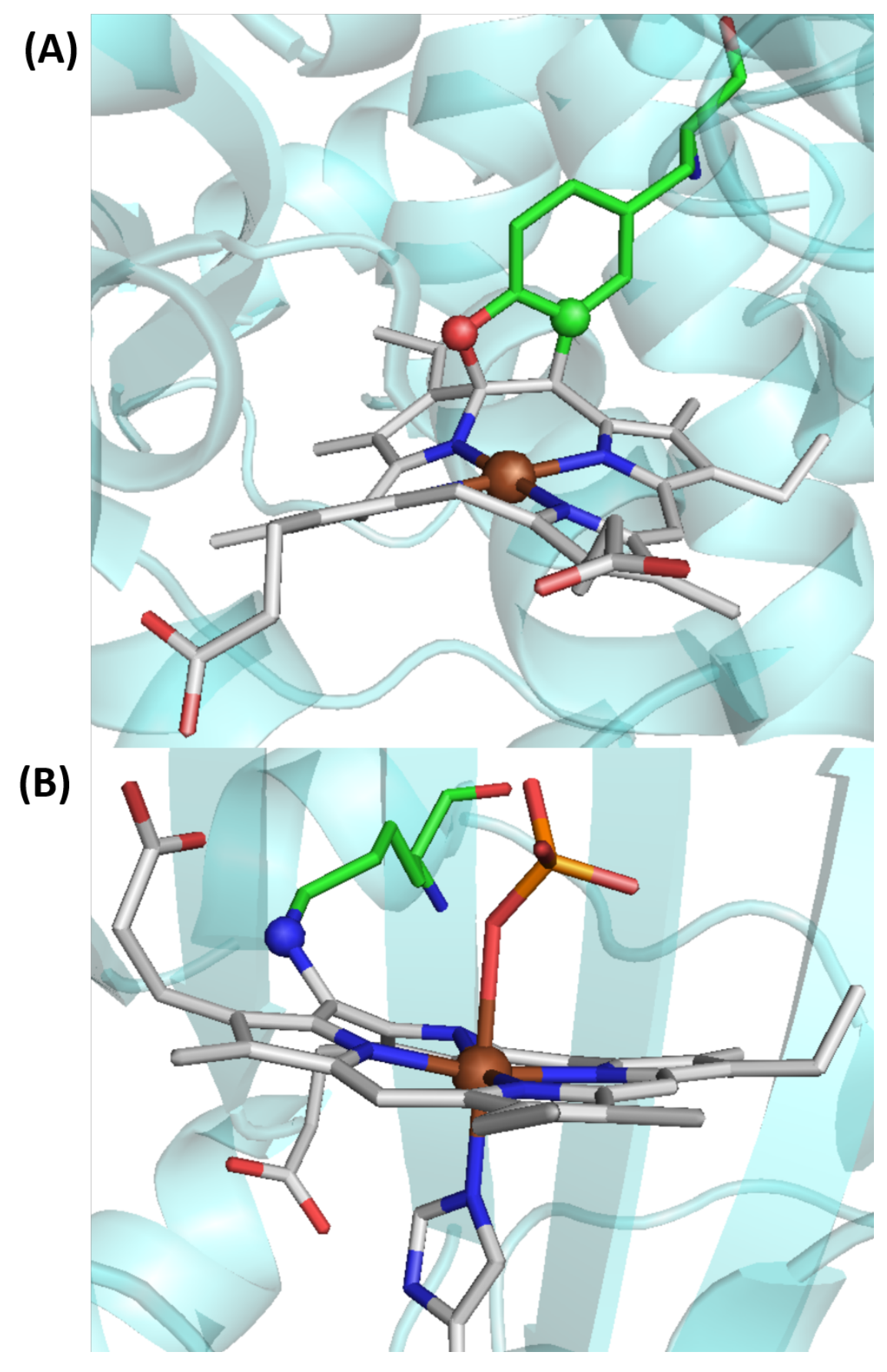

Figure S2. Isoporphyrin-like reactive intermediates in hydroxylamine oxido-reductases (A, PDB: 4FAS) ${ }^{7}$ and in cytochrome P460 (B, PDB: 2JE3). ${ }^{8}$ Further, these isoporphyrinlike species are covalently cross-linked to a nearby amino acid residue (highlighted in green: tyrosine for HAO and lysine for cyt. P460) that has functional and structural importance. This figure was generated using PyMOL (www.pymol.org). ${ }^{6}$ 

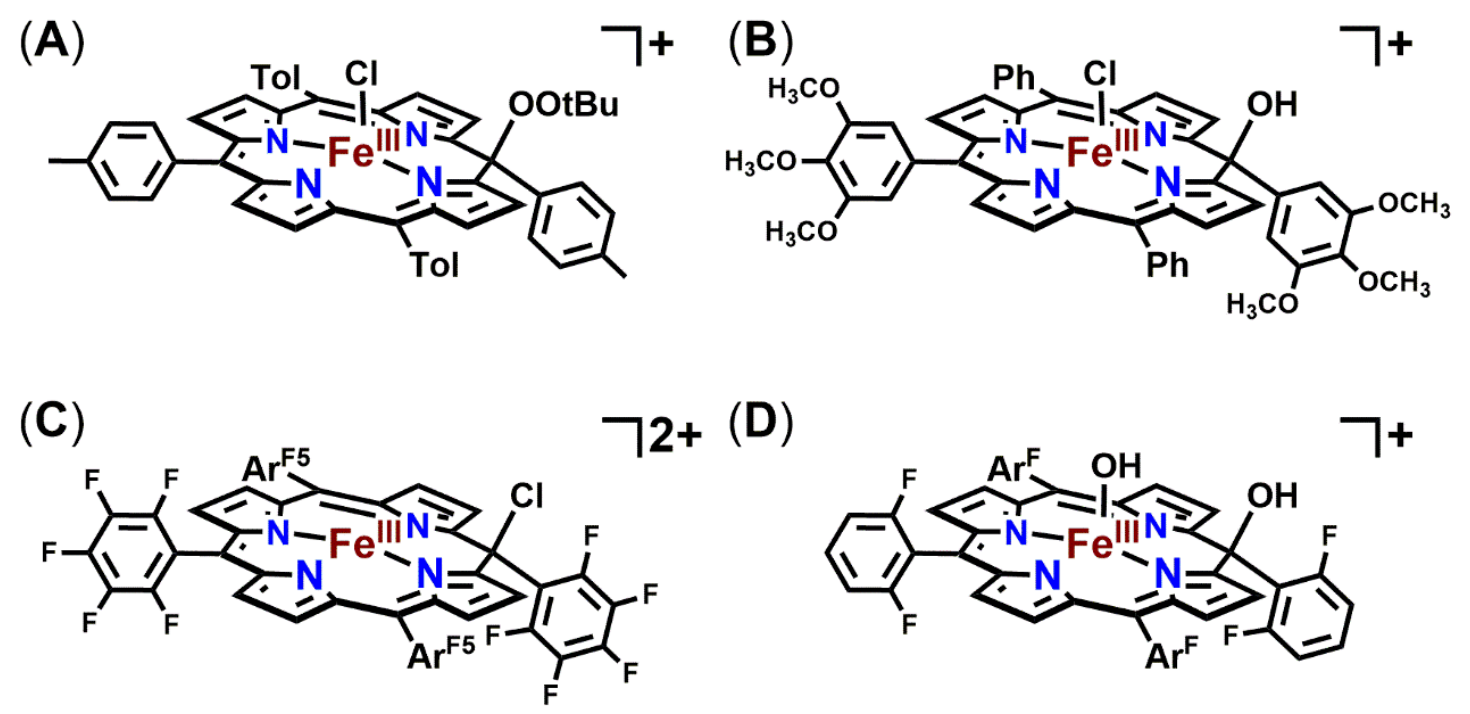

Figure S3. Previously reported iron(III) meso-X-isoporphyrin complexes (where $\mathrm{X}=$ tertbutylperoxy, hydroxy, or chloro groups). ${ }^{9-13}$ 
Table S1. Comparison of the UV-vis features of four previously published iron(III) meso$\mathrm{X}$-isoporphyrin complexes (depicted in Figure S3) with the four iron(III) meso-Xisoporphyrins synthesized herein with a chloro, azide, cyanide, or a substituted imidazole functionality.

\begin{tabular}{|c|c|c|}
\hline $\begin{array}{c}\text { Iron(III) meso-X- } \\
\text { isoporphyrins } \\
X=\end{array}$ & $\lambda_{\max }(\mathrm{nm})$ & Reference \\
\hline tert-Butylperoxy & $334,450 \mathrm{~nm}$ (Soret), 805, 881 (Q-band) & 10 \\
\hline Hydroxy & 350, 432 (Soret), 820, 920 (Q-band) & 12 \\
\hline Hydroxy & $825,920 \mathrm{~nm}$ (Q-band) & 13 \\
\hline Chloro & 359, 411 (Soret), 939 (Q-band) & 11 \\
\hline Chloro & 835, 934 (Q-band) & This work \\
\hline Azide & 375, 409 (Soret), 830, $931 \mathrm{~nm}$ (Q-band) & This work \\
\hline Cyanide & 374, 409 (Soret), 830, $931 \mathrm{~nm}$ (Q-band) & This work \\
\hline $\begin{array}{l}\text { 4,5-dimethyl } \\
\text { imidazole }\end{array}$ & 373, 410 (Soret), 840, 933 (Q-band) & This work \\
\hline
\end{tabular}


II. Cryo-ESI-MS $\left(-90^{\circ} \mathrm{C}\right)$ and UV-vis $\left(-90^{\circ} \mathrm{C}\right)$ \& EPR $(10 \mathrm{~K})$ spectroscopies following the formation of novel iron(III) meso-X-isoporphyrin complexes (where $\mathrm{X}=$ chloro, azide, cyanide, or 4,5-dimethylimidazole).
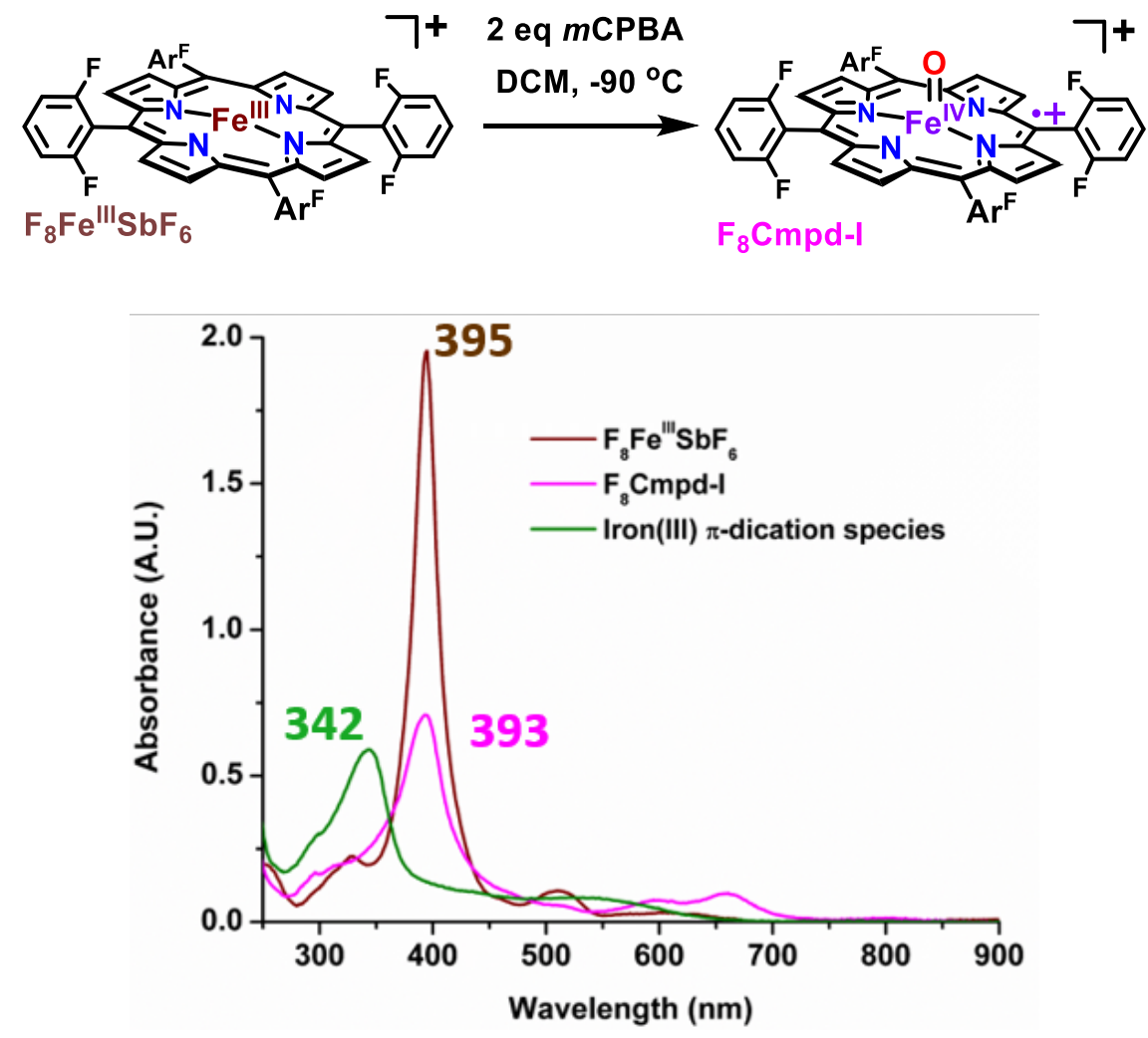


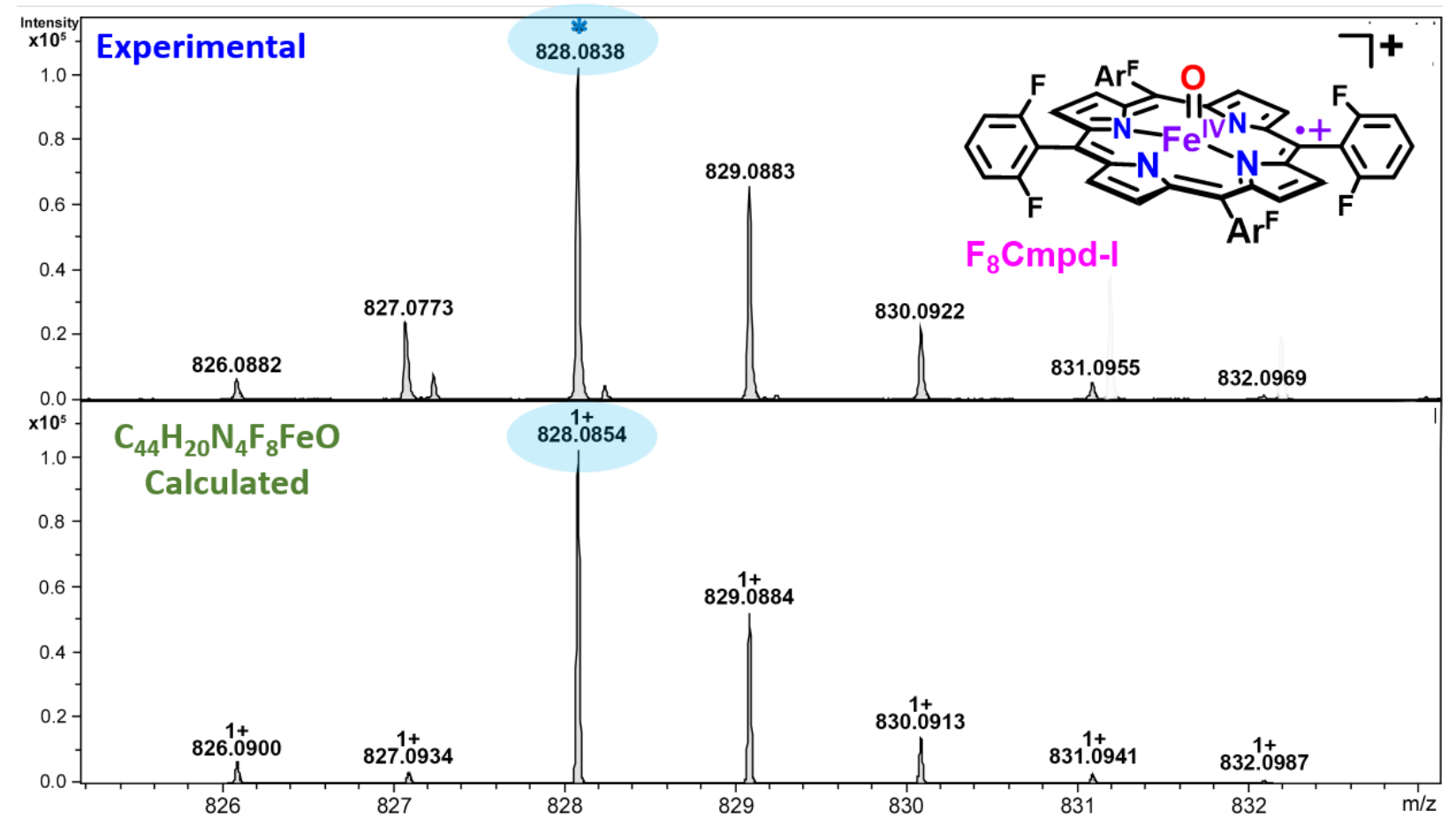

Figure S4. (Top) UV-vis spectra following the formation of $\mathrm{F}_{8} \mathrm{Cmpd}-\mathrm{I}$ (pink) in dichloromethane at $-90{ }^{\circ} \mathrm{C}$, wherein two equiv. of meta-chloroperoxybenzoic acid ( $m$ CPBA) was added to $0.01 \mathrm{mM} \mathrm{F}_{8} \mathrm{Fe}^{\mathrm{Ill}} \mathrm{SbF}_{6}$ (brown). Subsequent addition of 20 equiv. trifluoroacetic acid (TFA) to $\mathrm{F}_{8} \mathrm{Cmpd}$-I resulted in the iron(III) $\pi$-dication species (green). (Bottom) Enlarged Figure 3B of manuscript. Cryogenic ESI-MS (acquired in positive ion mode) of $\mathrm{F}_{8} \mathrm{Cmpd}-\mathrm{I}$ in dichloromethane at $-90^{\circ} \mathrm{C}$, detected at 829.0883 , in accordance with the calculated $\mathrm{m} / \mathrm{z}$. 

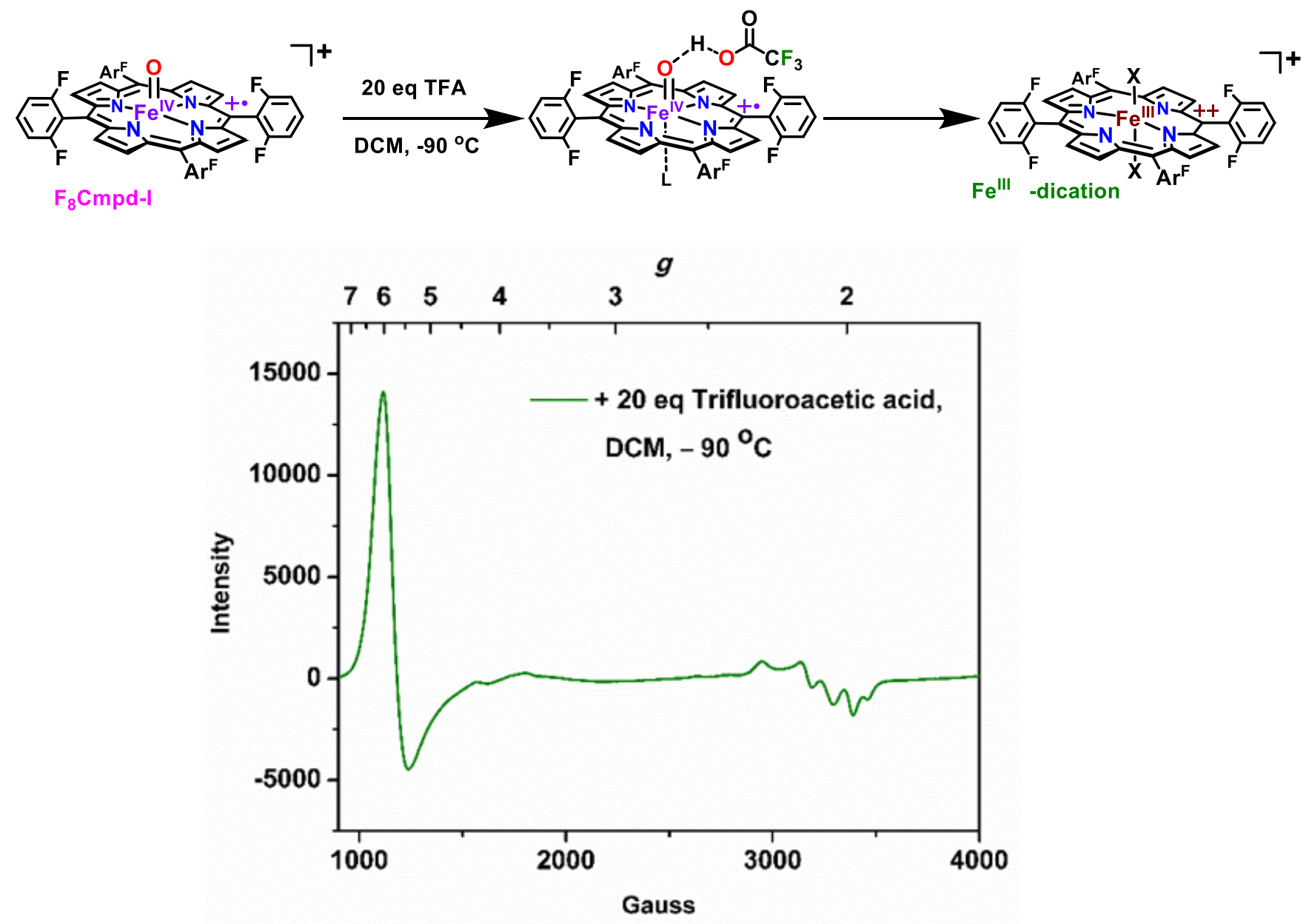

Figure S5. EPR spectrum of the iron(III) $\pi$-dication complex at $1 \mathrm{mM}$ in dichloromethane prepared at $-90{ }^{\circ} \mathrm{C}$ (acquired at $10 \mathrm{~K}$ ), where 20 equiv. TFA was added to $\mathrm{F}_{8} \mathrm{Cmpd}-\mathrm{I}$. The typical high-spin ferric signals were observed at $g=6$ and 2 . 

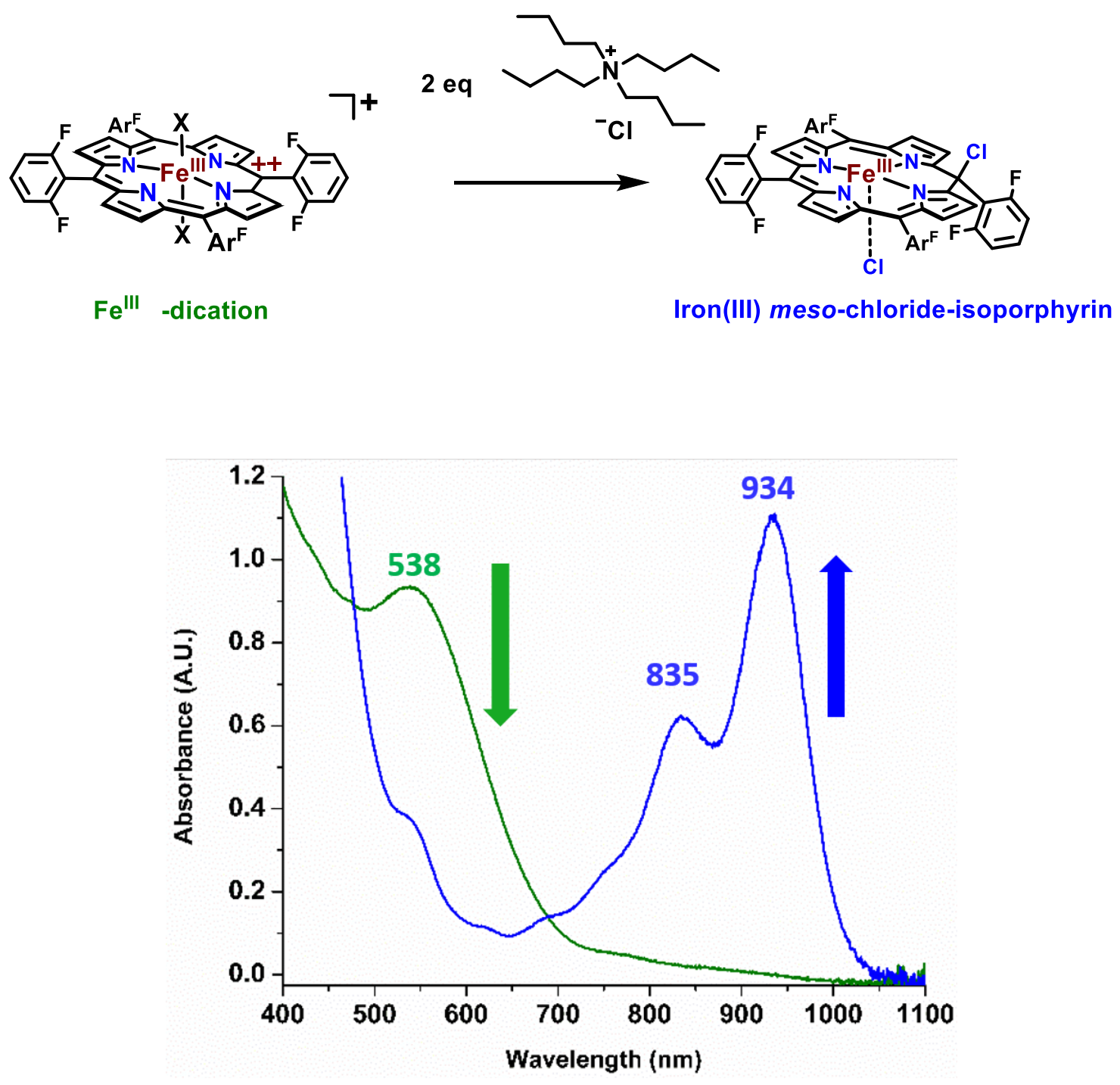


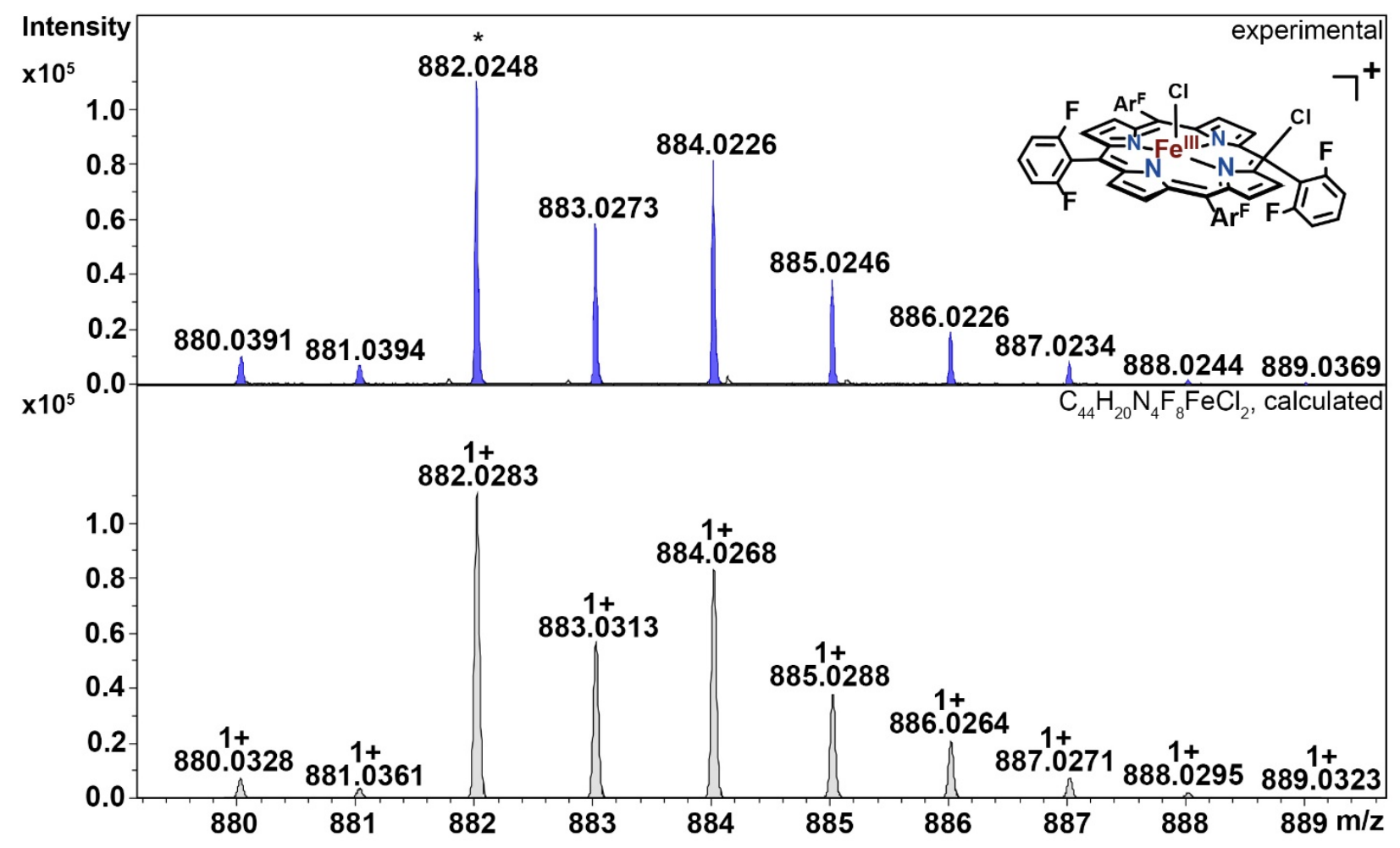

Figure S6. (A) UV-vis spectra following the formation of iron(III) meso-chloro-isoporphyrin in dichloromethane at $-90{ }^{\circ} \mathrm{C}$ at $0.1 \mathrm{mM}$, wherein two equiv. of tetrabutylammonium chloride was added to the iron(III) $\pi$-dication complex (green) and immediate isoporphyrin formation (blue; 538 to 835, $934 \mathrm{~nm}$ ) was observed. (B) Cryogenic ESI-MS of iron(III) meso-chloro-isoporphyrin in dichloromethane at $-90{ }^{\circ} \mathrm{C}$, detected at 882.0248 , in accordance with the calculated $\mathrm{m} / \mathrm{z}$. Simulated spectra are shown below that support complex identification. 

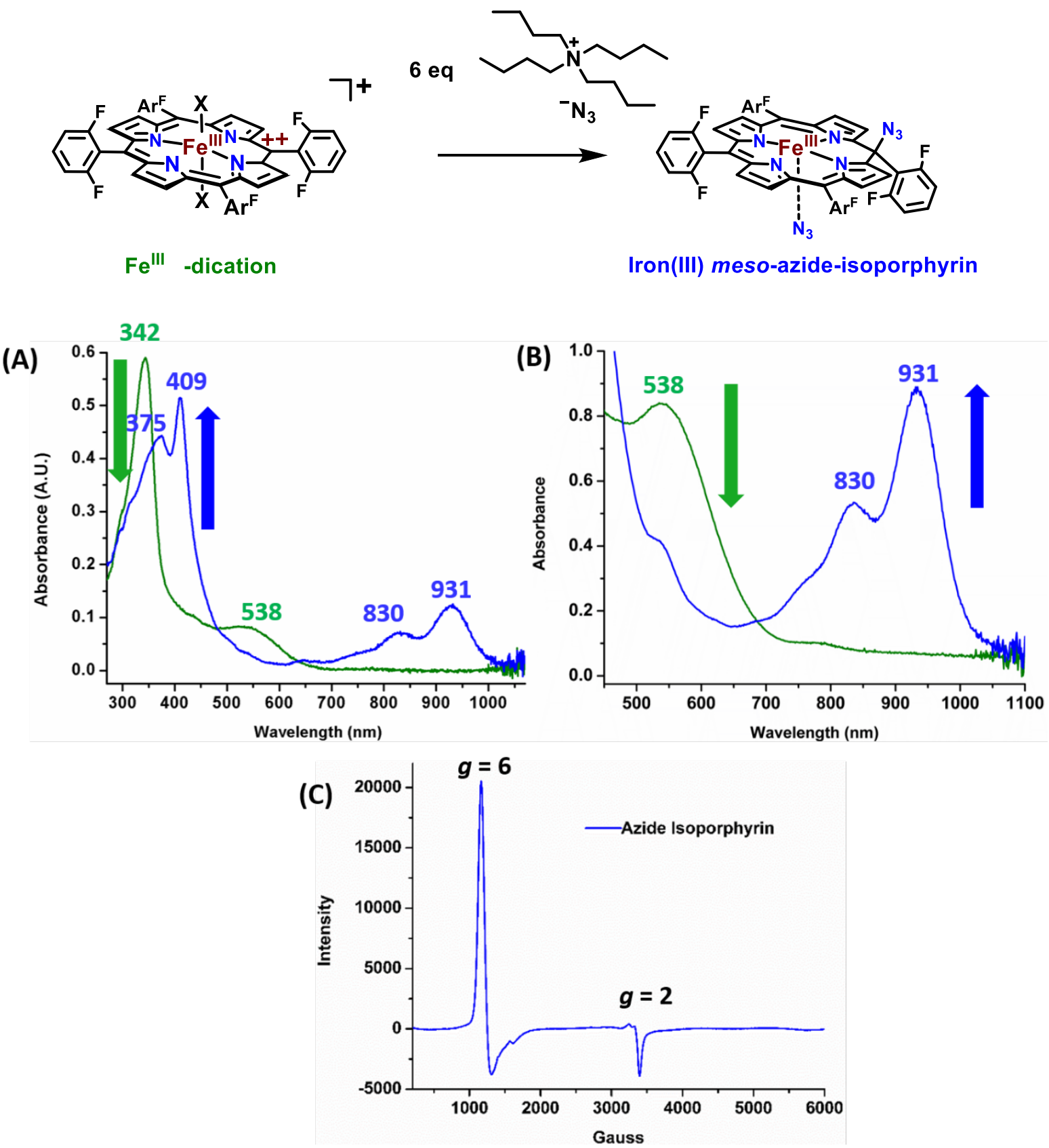

Figure S7. UV-vis spectra following the formation of iron(III) meso-azide-isoporphyrin in dichloromethane at $-90{ }^{\circ} \mathrm{C}$ at $0.01 \mathrm{mM}(\mathbf{A})$ and $0.1 \mathrm{mM}(B)$, wherein six equiv. of tetrabutylammonium azide was added to the iron(III) $\pi$-dication complex (green) resulting in immediate isoporphyrin formation (blue). EPR spectra (C) of iron(III) meso-azideisoporphyrin at $1 \mathrm{mM}$ in dichloromethane prepared at $-90^{\circ} \mathrm{C}$ (acquired at $10 \mathrm{~K}$ ), where 6 equiv. $\mathrm{TBAN}_{3}$ was added to the iron(III) $\pi$-dication complex. The typical high-spin ferric signals were observed at $g=6$ and 2. Both the UV-vis and EPR spectra of the isoporphyrin are analogous to that of which is reported for the iron(III) meso-chloroisoporphyrin by Fujii and co-workers. ${ }^{11}$ 


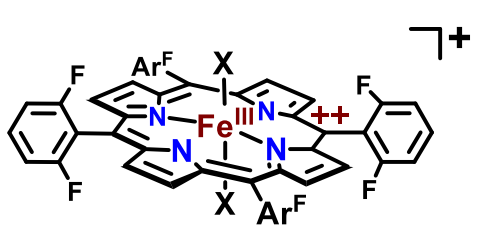

$\mathrm{Fe}^{\text {III }}$-dication

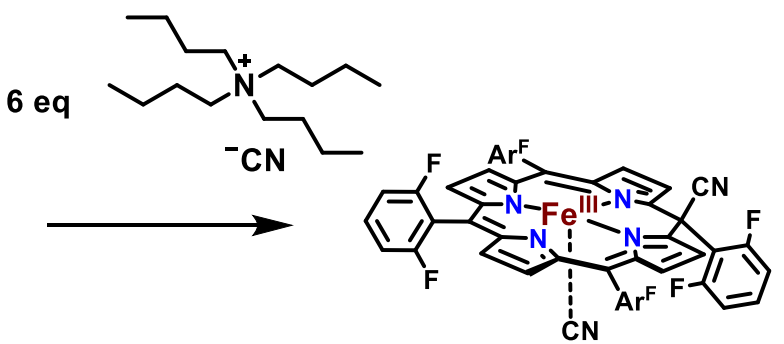

Iron(III) meso-cyanide-isoporphyrin
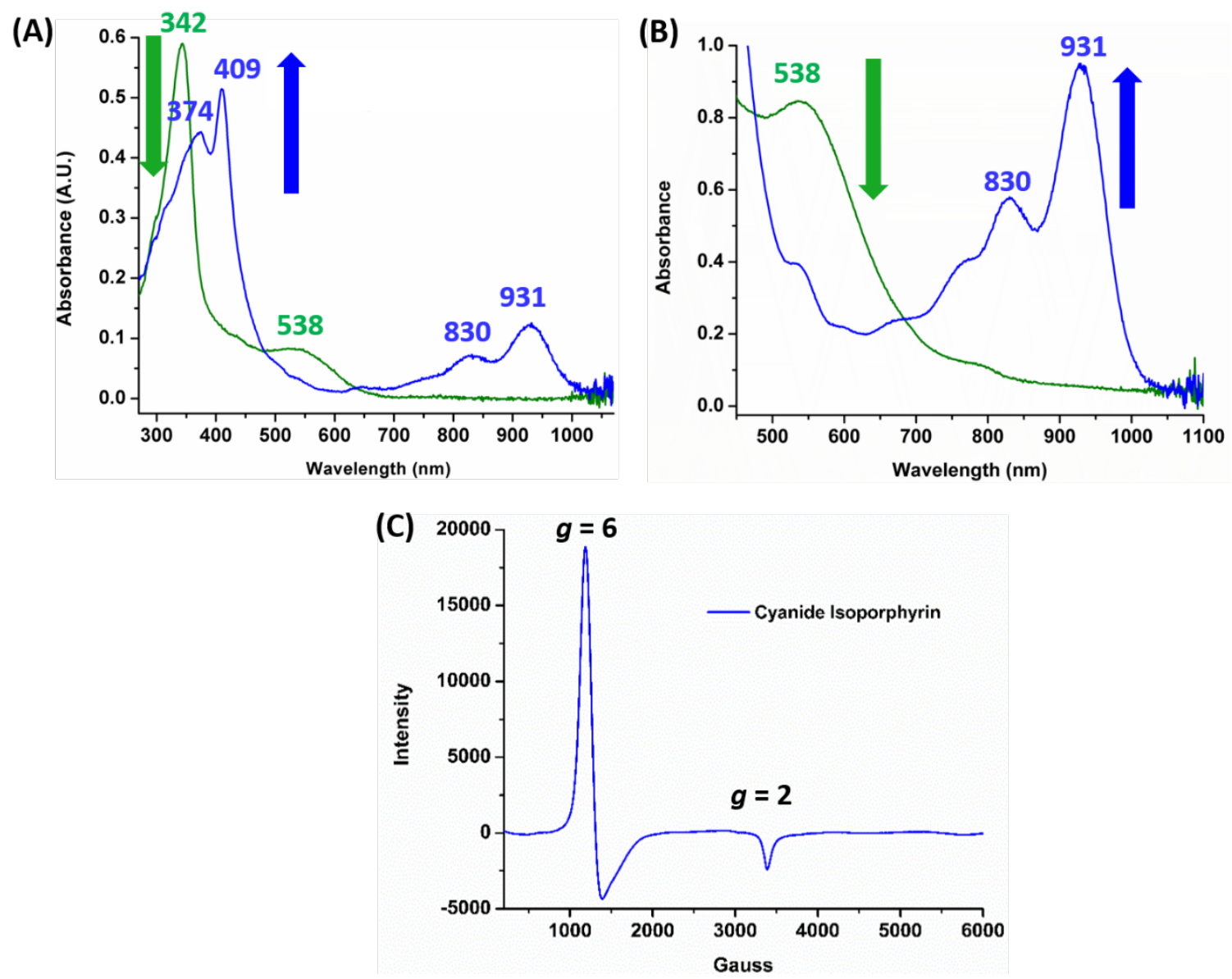

Figure S8. UV-vis spectra following the formation of iron(III) meso-cyanide-isoporphyrin in dichloromethane at $-90{ }^{\circ} \mathrm{C}$ at $0.01 \mathrm{mM}(\mathbf{A})$ and $0.1 \mathrm{mM}(\mathbf{B})$, wherein six equiv. of tetrabutylammonium cyanide was added to the iron(III) $\pi$-dication complex (green) resulting in immediate isoporphyrin formation (blue). EPR spectra of iron(III) mesocyanide-isoporphyrin at $1 \mathrm{mM}$ in dichloromethane prepared at $-90{ }^{\circ} \mathrm{C}$ (acquired at $10 \mathrm{~K}$ ), where 6 equiv. tetrabutylammonium cyanide was added to the iron(III) $\pi$-dication complex. The typical high-spin ferric signals were observed at $g=6$ and 2 . Both the UVvis and EPR spectra of the isoporphyrin are analogous to that of which is reported for the iron(III) meso-chloro-isoporphyrin by Fujii and co-workers. ${ }^{11}$ 


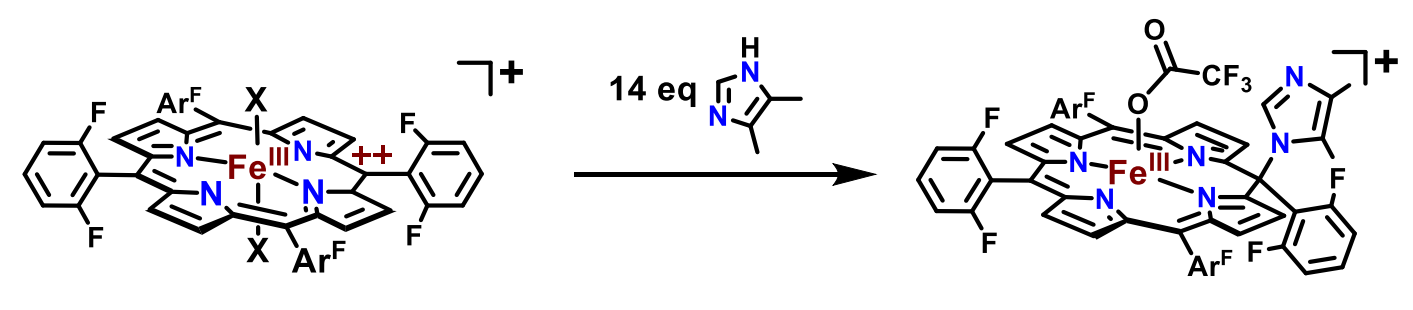

$\mathrm{Fe}^{\text {III }}$-dication

Iron(III) meso-4,5-dimethylimidazole-isoporphyrin

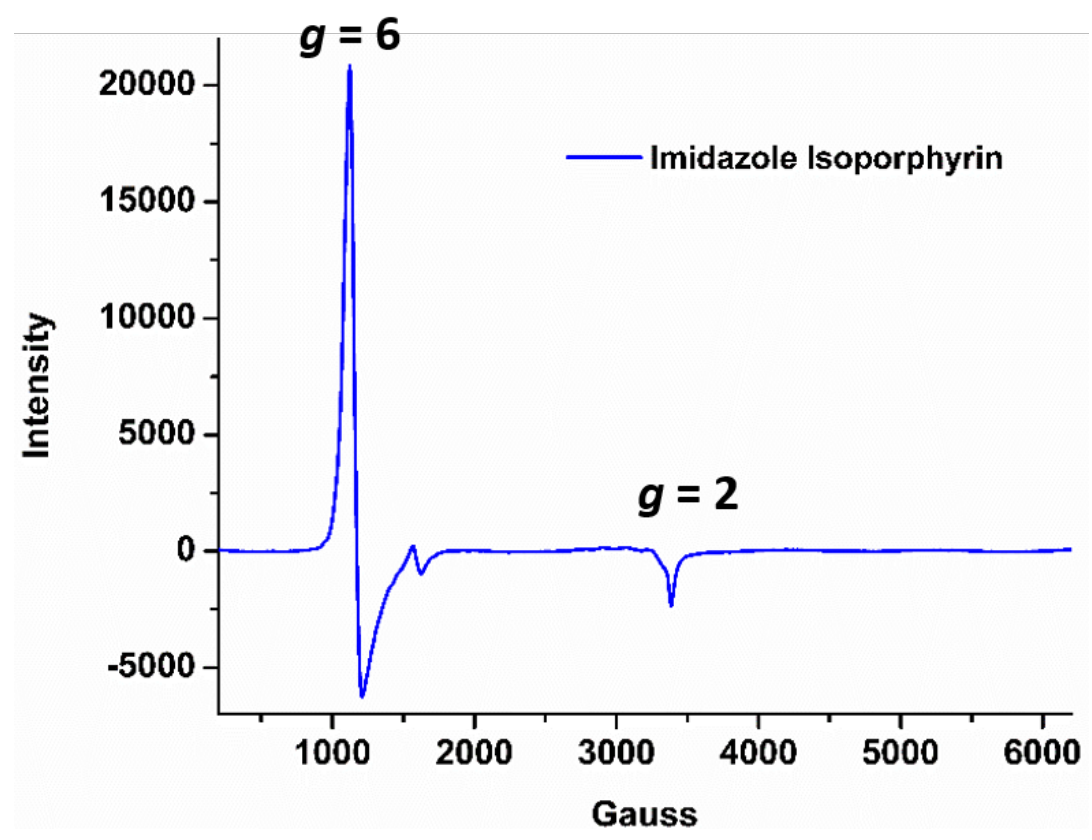

Figure S9. EPR spectra of iron(III) meso-4,5-dimethylimidazole-isoporphyrin at $1 \mathrm{mM}$ in dichloromethane prepared at $-90{ }^{\circ} \mathrm{C}$ (acquired at $10 \mathrm{~K}$ ), where 14 equiv. 4,5dimethylimidazole was added to the iron(III) $\pi$-dication complex. The typical high-spin ferric signals were observed at $g=6$ and 2. Both the UV-vis and EPR spectra of the isoporphyrin are analogous to that of which is reported for the iron(III) meso-chloroisoporphyrin by Fujii and co-workers. ${ }^{11}$ 

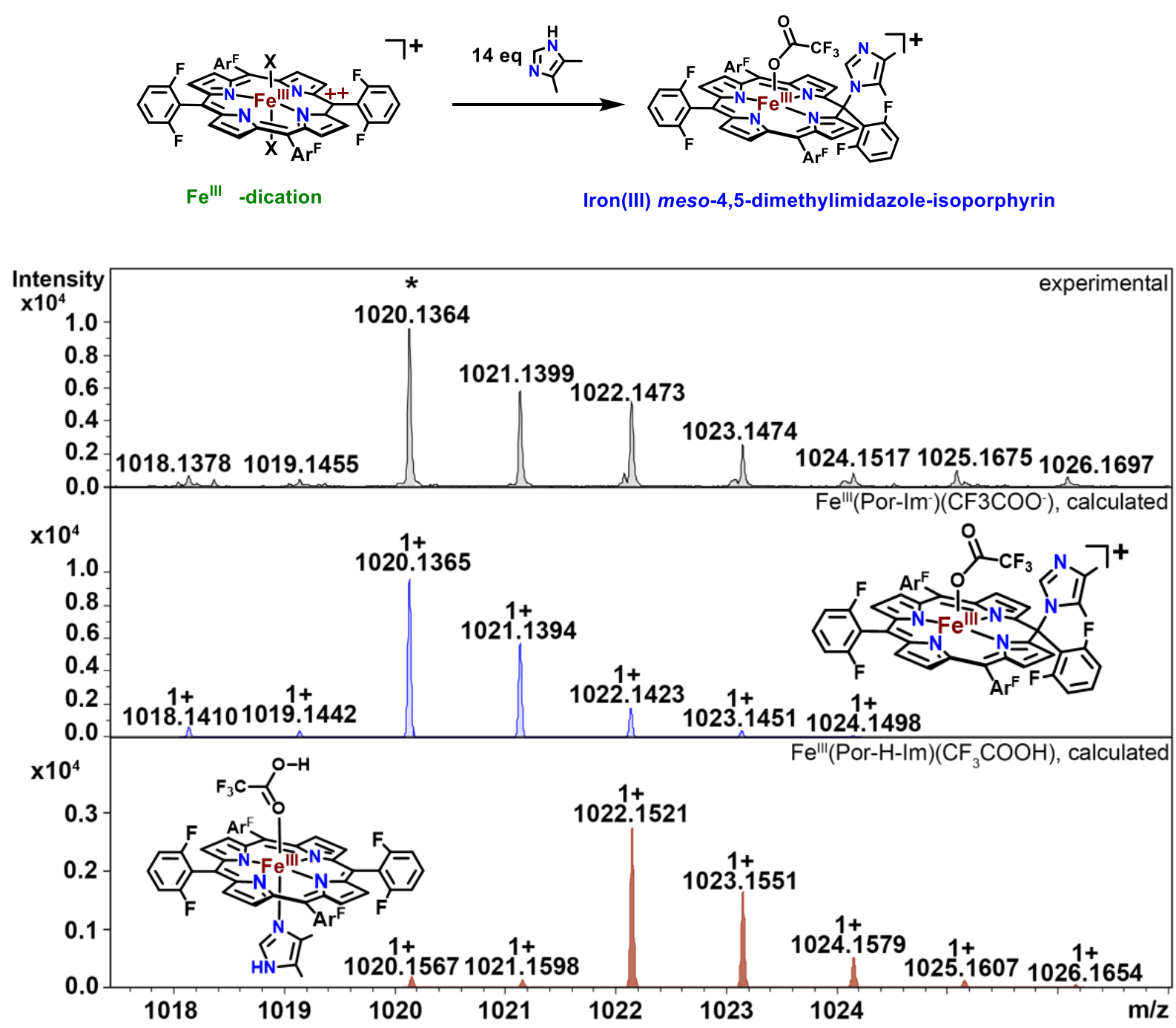

Figure S10. Cryogenic ESI-MS (acquired in positive ion mode) of iron(III) meso-4,5dimethylimidazole-isoporphyrin in dichloromethane at $-90^{\circ} \mathrm{C}$, detected at 1020.1364 , in accordance with the calculated $\mathrm{m} / \mathrm{z}$. A minor ferric impurity coordinated to TFA and 4,5dimethylimidazole was also detected at $1022.1473 \mathrm{~m} / \mathrm{z}$. Simulated spectra are shown below that support complex identification. 


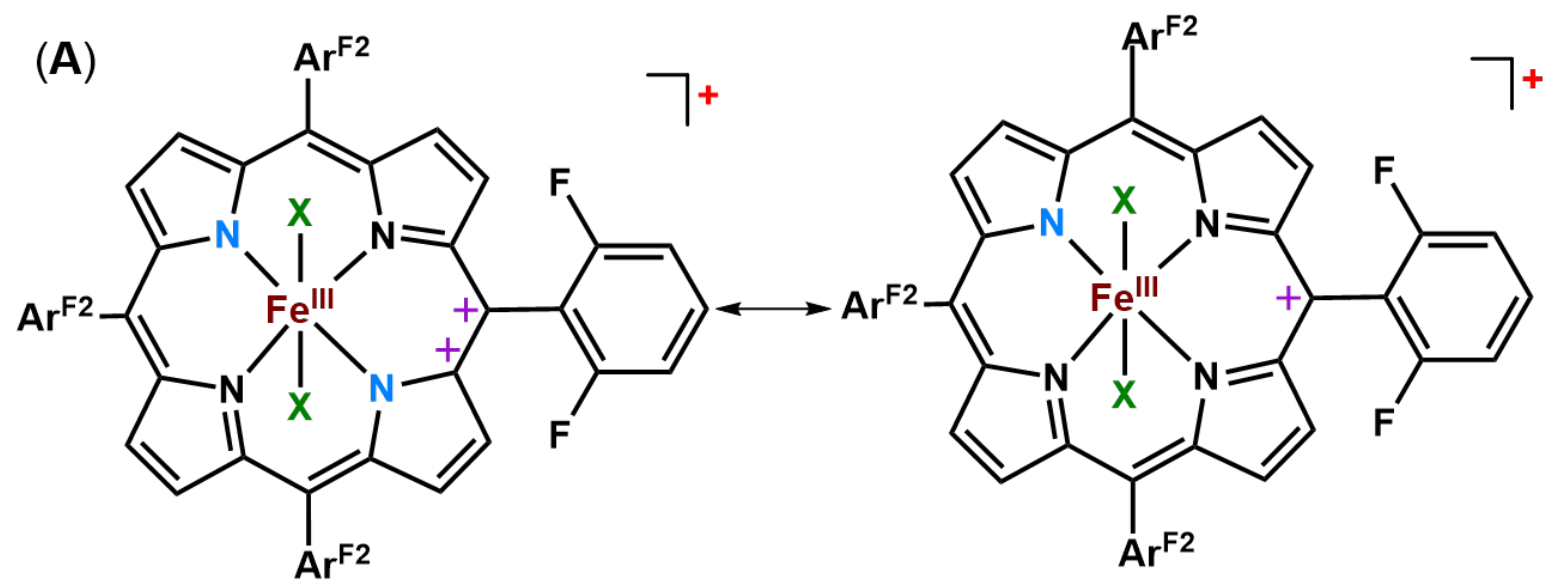

Overall Charge $=3-2-2+2=1$

(B)

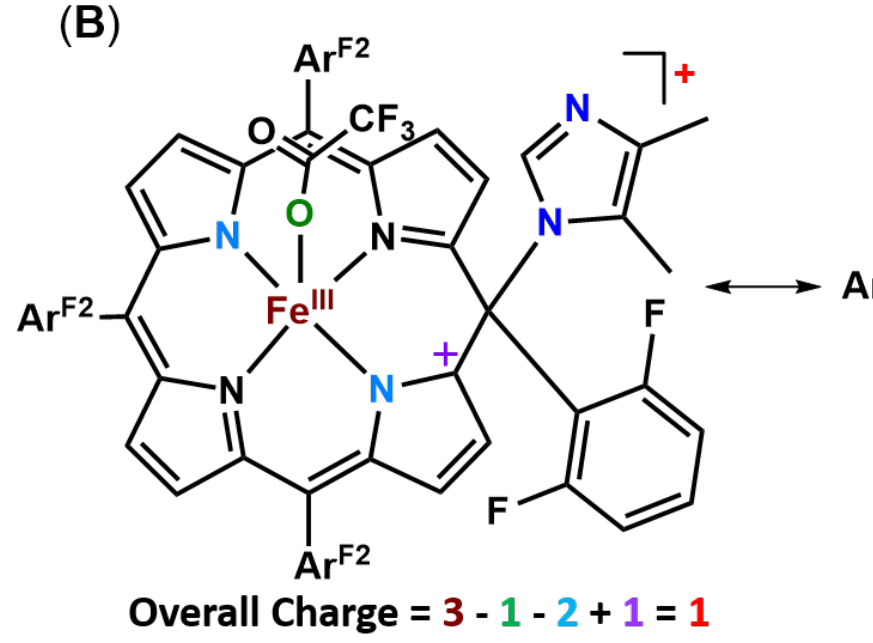

Overall Charge= $3-2-1+1=1$

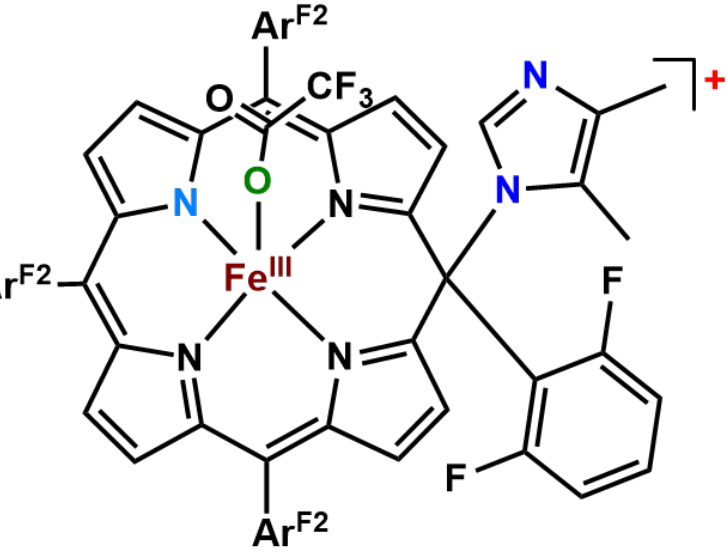

Overall Charge $=3-1-1=1$

(C)

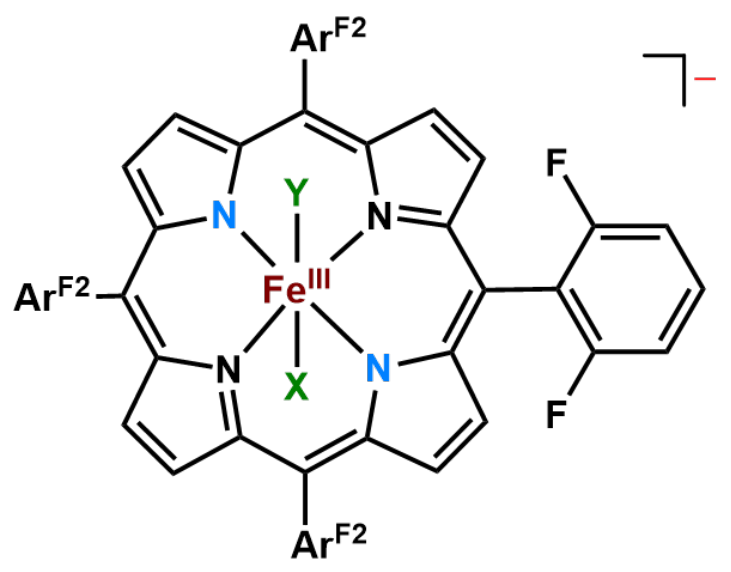

$Y=$ Trifluoroacetate

$X=4,5$-dimethylimidazolate

Overall Charge $=3-2-2=-1$

Figure S11. (A) Iron(III) $\pi$-dication, (B) iron(III) meso-4,5-dimethylimidazole-isoporphyrin, and (C) iron(III) porphyrin with two anionic ligands bound axially depicted from a top perspective to aid in the determination of the charge of the complexes. Both are +1 charged complexes. 


\section{III. ${ }^{2} \mathrm{H}-\mathrm{NMR}$ spectroscopy at $-90^{\circ} \mathrm{C}$ following the formation of novel iron(III) meso- $X$-isoporphyrin complexes (where $X=$ azide or cyanide).}

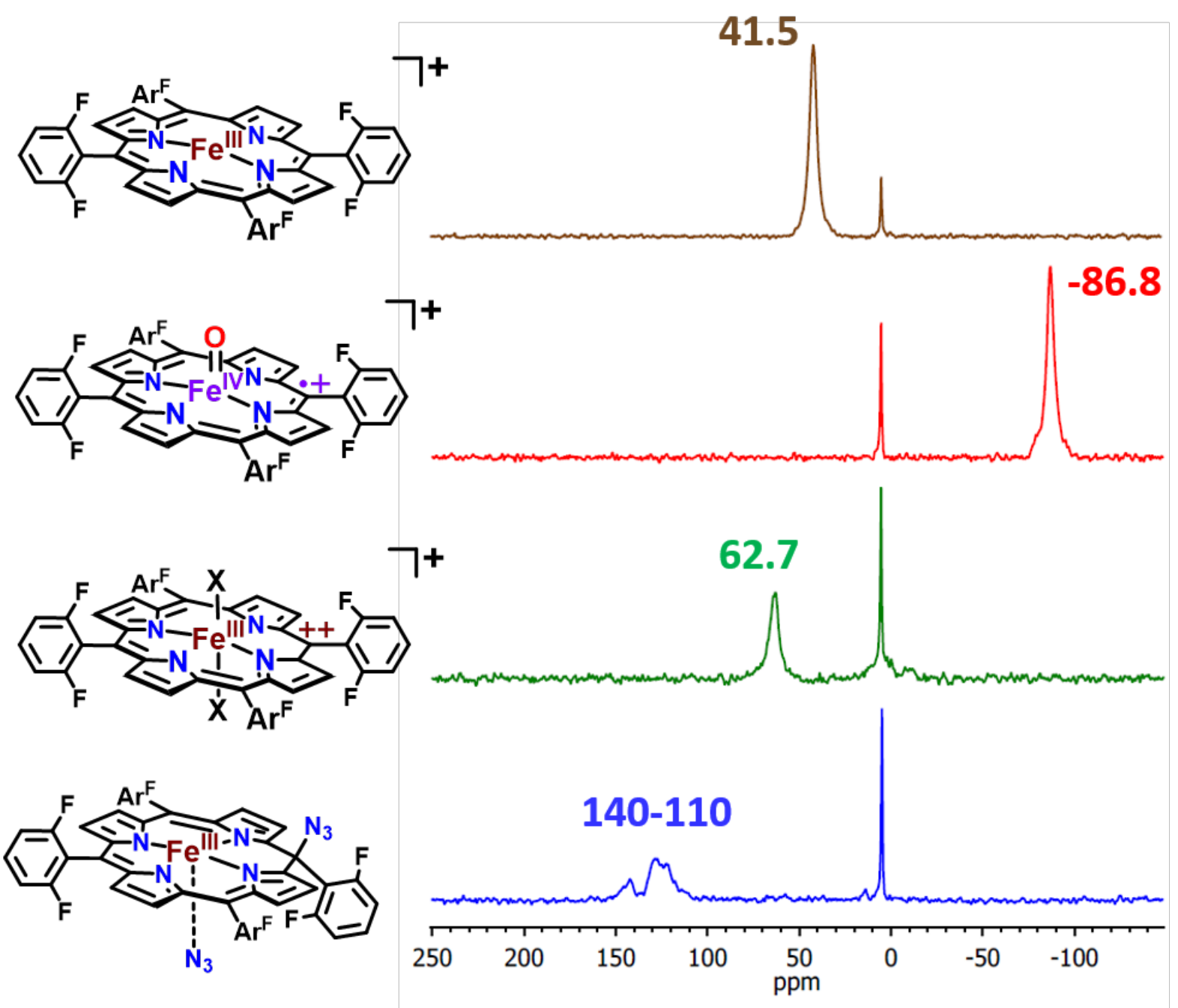

Figure S12. ${ }^{2} \mathrm{H}-\mathrm{NMR}$ spectra (wherein the pyrroles are deuterated, the starting material employed was $d_{8}-\mathrm{F}_{8} \mathrm{Fe}^{\mathrm{III}} \mathrm{SbF}_{6}$ ) following the formation of iron(III) meso-azide isoporphyrin in dichloromethane at $-90^{\circ} \mathrm{C}$. All spectra were calibrated to residual deuterated DCM at $5.32 \mathrm{ppm}$. A $5 \mathrm{mM}$ solution of $\mathrm{F}_{8} \mathrm{Fe}^{\text {Ill }} \mathrm{SbF}_{6}$ in dichloromethane was cooled to $-90{ }^{\circ} \mathrm{C}(41.5$ ppm), upon which 2 equiv. of $m$ CPBA was added to form $\mathrm{F}_{8} \mathrm{Cmpd}-\mathrm{I}$ (-86.8 ppm). Subsequent addition of 20 equiv. TFA and then 6 equiv. tetrabutylammonium azide results in the formation of the iron(III) $\pi$-dication complex $(62.7 \mathrm{ppm})$ and the iron(III) meso-azide-isoporphyrin complex (140-110 ppm), respectively. The ${ }^{2} \mathrm{H}-\mathrm{NMR}$ signatures of the $\mathrm{F}_{8} \mathrm{Cmpd}-\mathrm{I}$ and isoporphyrin complexes match the ${ }^{2} \mathrm{H}-\mathrm{NMR}$ acquired at $-80^{\circ} \mathrm{C}$ in dichloromethane for $\mathrm{F}_{20} \mathrm{Cmpd}-\mathrm{I}\left(\mathrm{F}_{20}=\right.$ tetrakis(pentafluorophenyl)-porphyrinate) and the iron(III) meso-chloro-isoporphyrin reported by Fujii and co-workers. ${ }^{11}$ It is of note that the signal is very weak for the isoporphyrin complex due to the meso functionality causing the deuterated pyrrole signals to be inequivalent. 


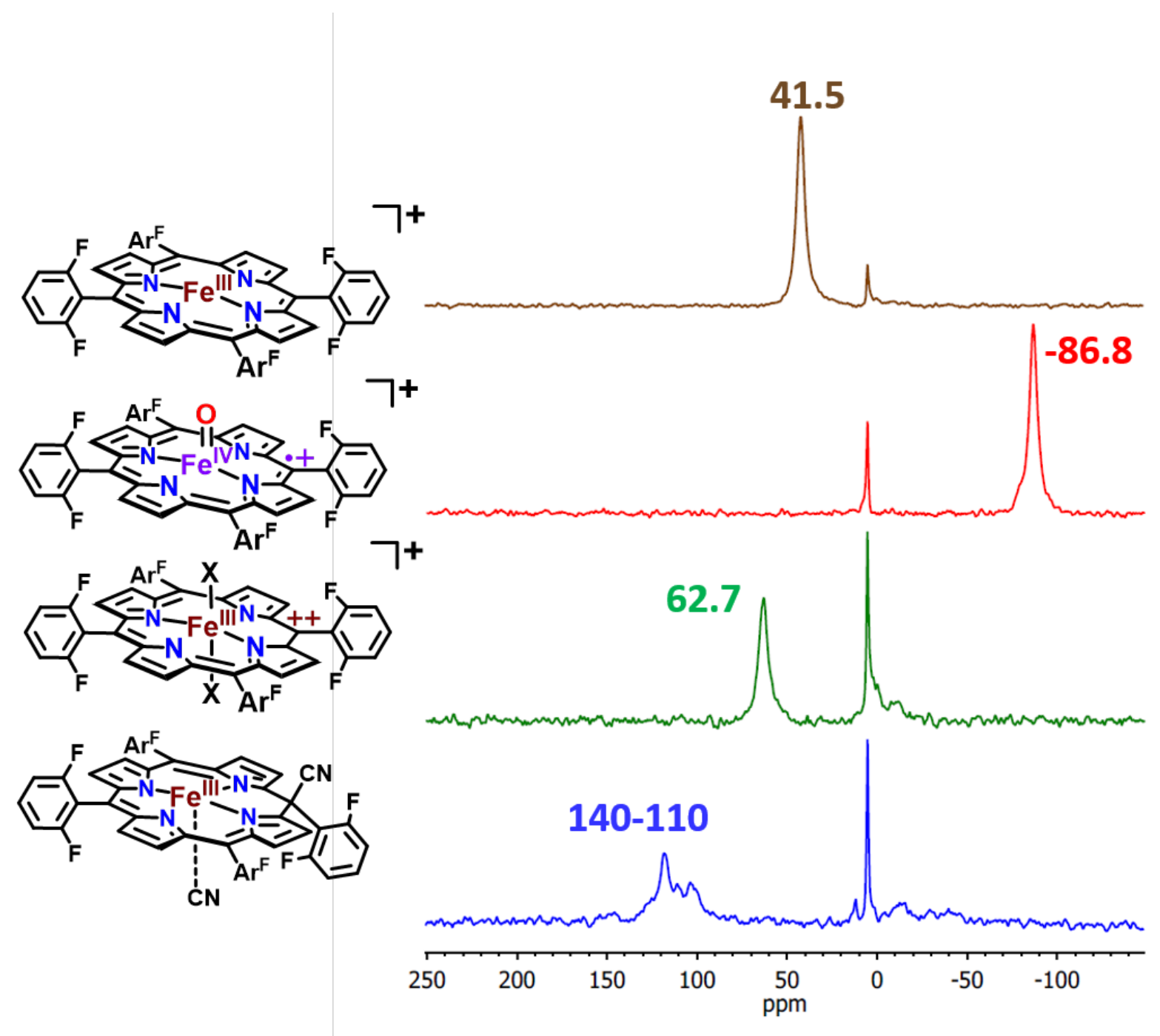

Figure S13. ${ }^{2} \mathrm{H}-\mathrm{NMR}$ spectra (wherein the pyrroles are deuterated, the starting material employed was $d_{8}-\mathrm{F}_{8} \mathrm{Fe}^{\mathrm{Ill}} \mathrm{SbF}_{6}$ ) following the formation of iron(III) meso-cyanideisoporphyrin in dichloromethane at $-90^{\circ} \mathrm{C}$. All spectra were calibrated to residual deuterated $\mathrm{DCM}$ at $5.32 \mathrm{ppm}$. A $5 \mathrm{mM}$ solution of $\mathrm{F}_{8} \mathrm{Fe}^{\mathrm{lll}} \mathrm{SbF}_{6}$ in dichloromethane was cooled to $-90^{\circ} \mathrm{C}$ ( $\left.41.5 \mathrm{ppm}\right)$, upon which 2 equiv. of $m \mathrm{CPBA}$ was added to form $\mathrm{F}_{8} \mathrm{Cmpd}-$ I (-86.8 ppm). Subsequent addition of 20 equiv. TFA and then 6 equiv. tetrabutylammonium cyanide results in the formation of the iron(III) $\pi$-dication complex (62.7 ppm) and the iron(III) meso-cyanide-isoporphyrin complex (140 - $110 \mathrm{ppm}$ ), respectively. The ${ }^{2} \mathrm{H}-\mathrm{NMR}$ signatures of the $\mathrm{F}_{8} \mathrm{Cmpd}-\mathrm{I}$ and isoporphyrin complexes match the ${ }^{2} \mathrm{H}-\mathrm{NMR}$ acquired at $-80^{\circ} \mathrm{C}$ in dichloromethane for $\mathrm{F}_{20} \mathrm{Cmpd}-\mathrm{I}$ and the iron(III) mesochloro-isoporphyrin reported by Fujii and co-workers. ${ }^{11}$ It is of note that the signal is very weak for the isoporphyrin complex due to the meso functionality causing the deuterated pyrrole signals to be inequivalent. 
IV. Cryo-ESI-MS and UV-vis $\left(-90^{\circ} \mathrm{C}\right),{ }^{2} \mathrm{H}-\mathrm{NMR}\left(-90^{\circ} \mathrm{C}\right)$, \& EPR $(10 \mathrm{~K})$ spectroscopies following the reactivity of the iron(III) meso-4,5-dimethylimidazole-isoporphyrin complex.

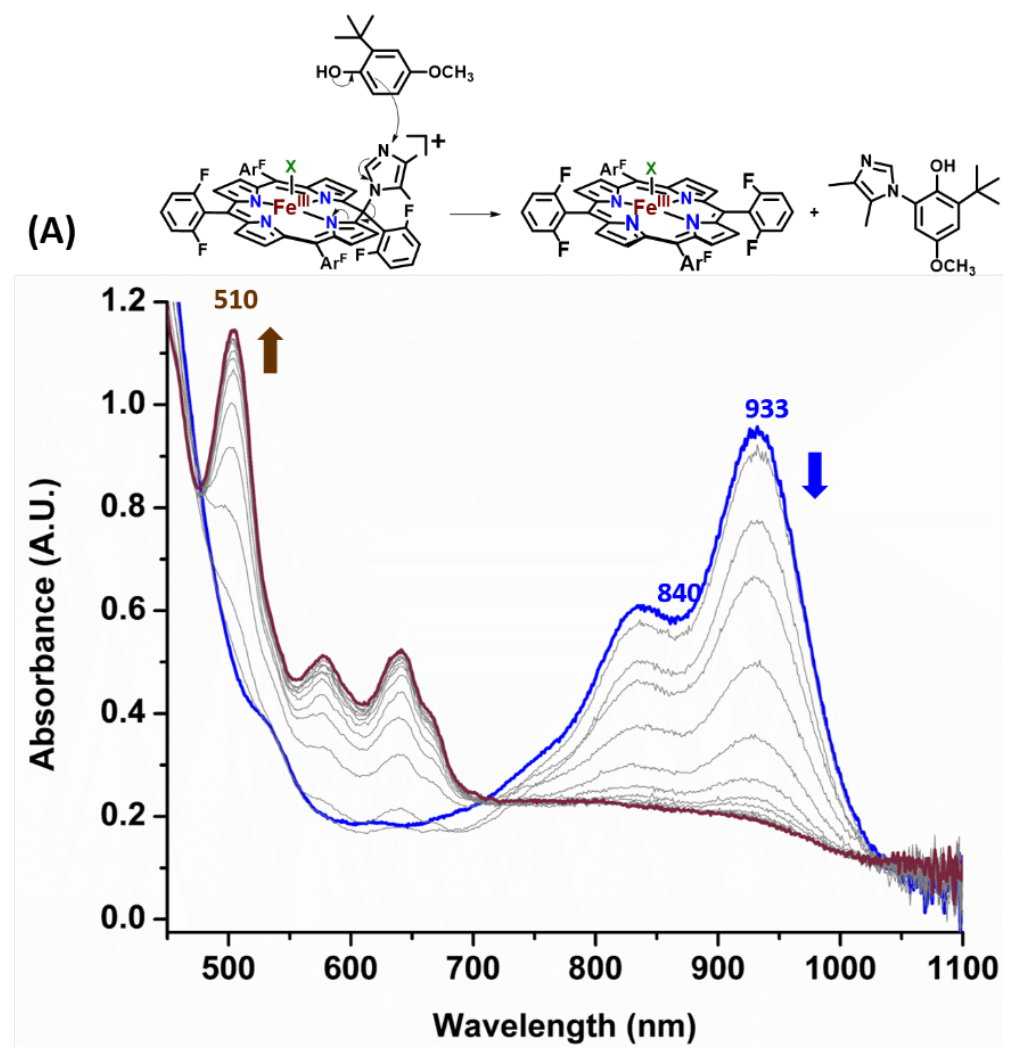



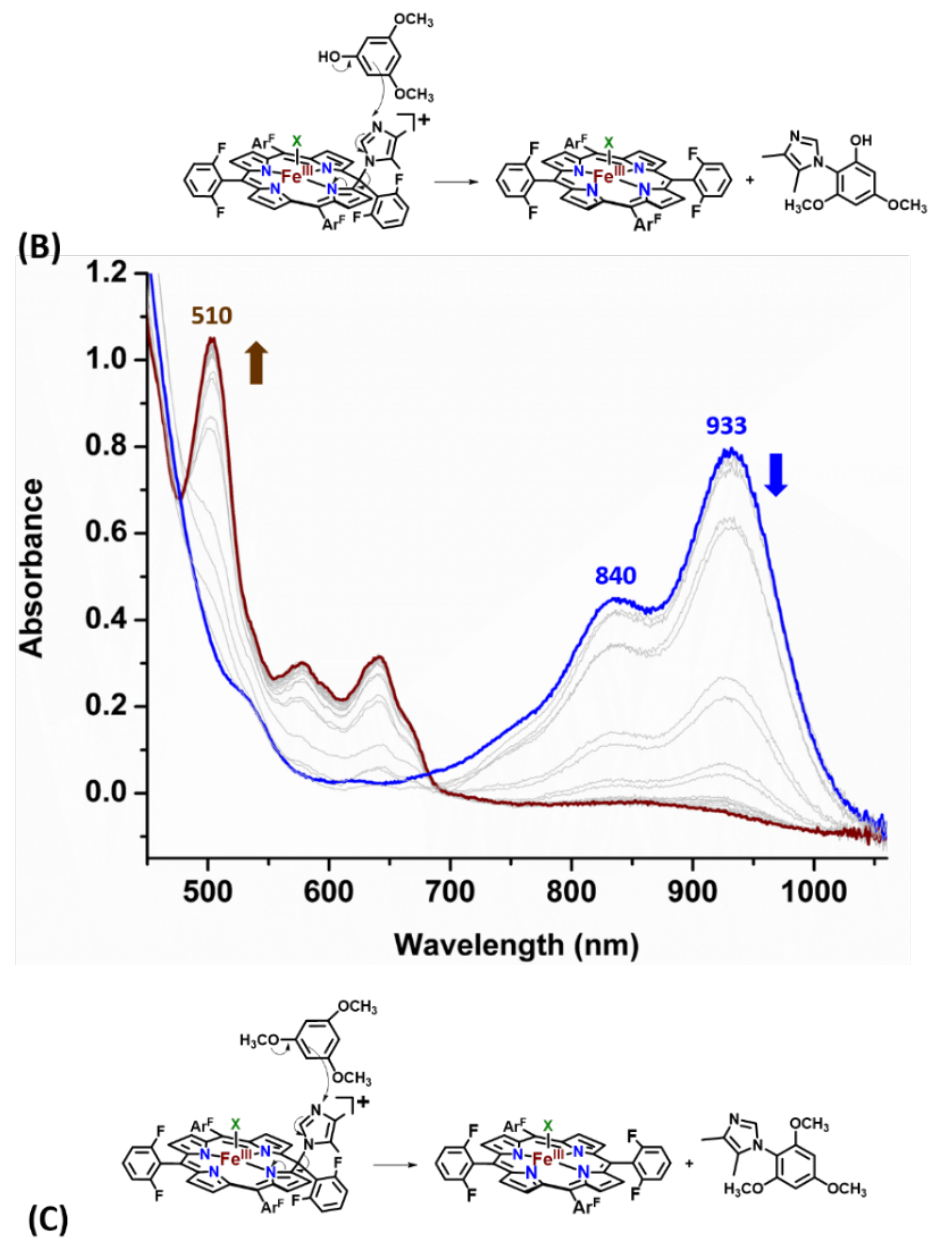

(C)

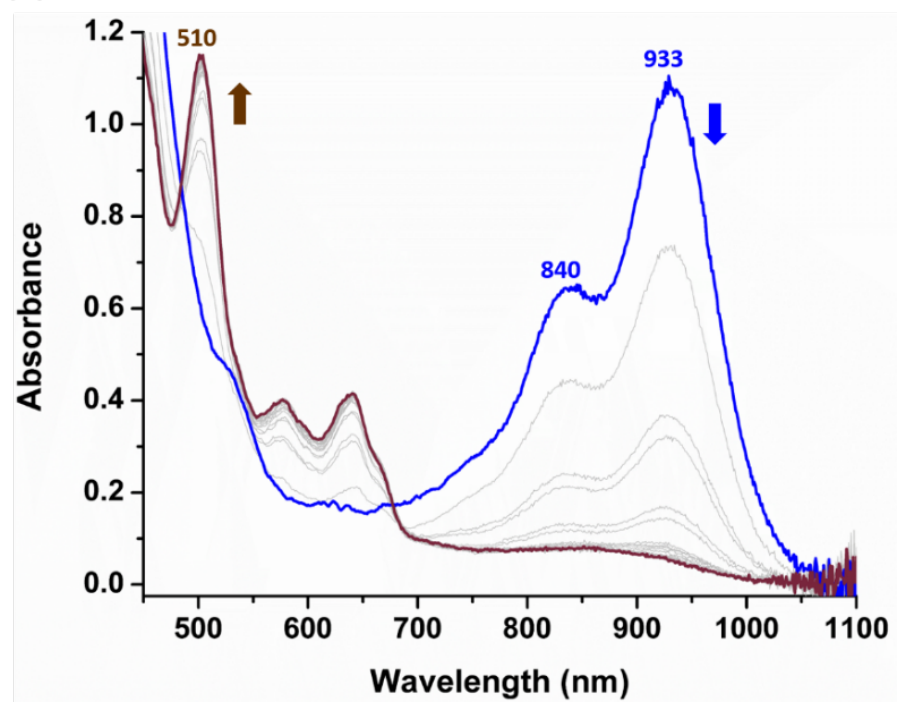

Figure S14. UV-vis spectra monitoring the disappearance of iron(III) meso-4,5dimethylimidazole-isopoprphyrin DCM at $-90{ }^{\circ} \mathrm{C}$ (from blue to brown) upon addition of 100 equiv. 2-tert-butyl-4-methoxyphenol (A), 50 equiv. 3,5-dimethoxyphenol (B), or 50 equiv. 1,3,5-trimethoxybenzene $(\mathbf{C})$. The resulting UV-vis spectra in brown is comparable to that of the starting material naked ferric species, $\mathrm{F}_{8} \mathrm{Fe}^{\mathrm{Ill}} \mathrm{SbF}_{6}$, however it is drawn with a possible $\mathrm{X}$ ligand which may be imidazole, water, TFA, etc. 

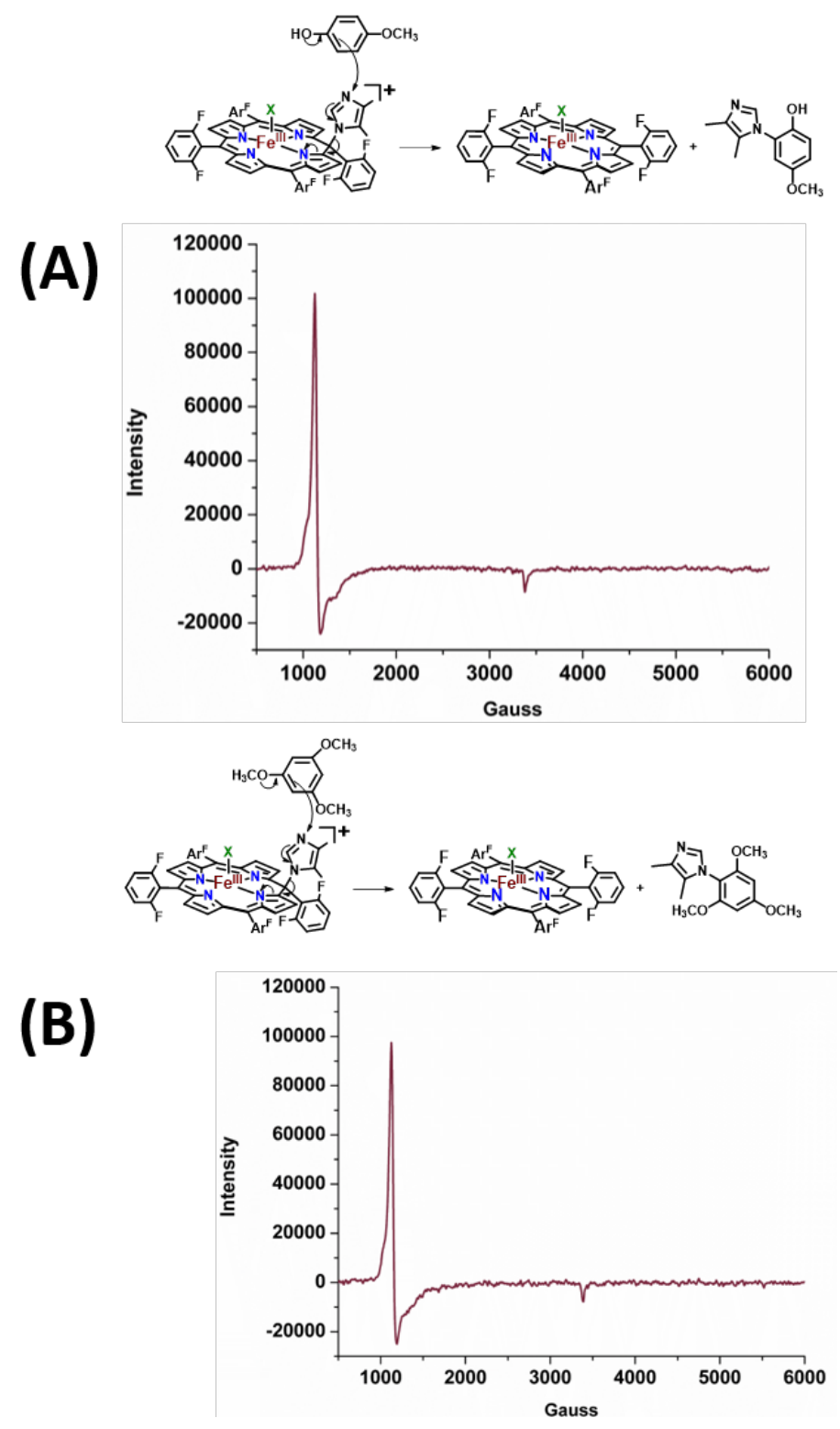

Figure S15. EPR spectra (acquired at $10 \mathrm{~K}$ ) following the addition of 50 equiv. 4methoxyphenol (A) and 50 equiv. 1,3,5-trimethoxybenzene (B) to $1 \mathrm{mM}$ iron(III) meso4,5-dimethylimidazole-isopoprphyrin in DCM at $-90^{\circ} \mathrm{C}$. The resulting EPR spectra in brown is comparable to that of the starting material naked ferric species, $\mathrm{F}_{8} \mathrm{Fe}^{\mathrm{Ill}} \mathrm{SbF}_{6}$, however it is drawn with a possible $\mathrm{X}$ ligand which may be imidazole, water, TFA, etc. 


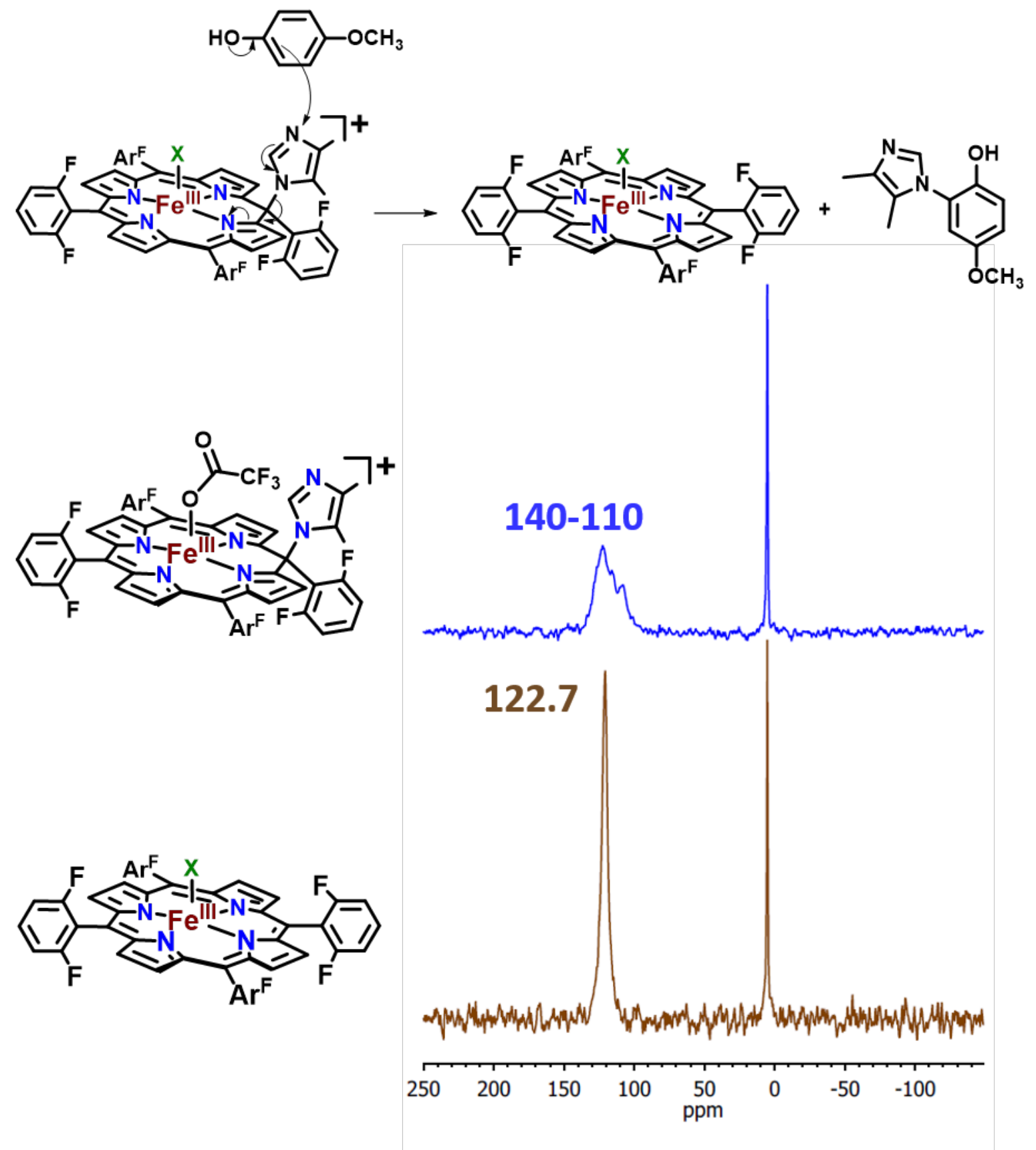

Figure S16. ${ }^{2} \mathrm{H}-\mathrm{NMR}$ spectra (wherein the pyrroles are deuterated, the starting material employed was $d_{8}-\mathrm{F}_{8} \mathrm{Fe}^{\text {lll }} \mathrm{SbF}_{6}$ ) following the addition of 50 equiv. 4-methoxyphenol to 5 $\mathrm{mM}$ iron(III) meso-4,5-dimethylimidazole-isopoprphyrin in DCM at $-90^{\circ} \mathrm{C}$. Spectra were calibrated to residual deuterated DCM at $5.32 \mathrm{ppm}$. The resulting ${ }^{2} \mathrm{H}-\mathrm{NMR}$ spectra in brown is thought to be the starting material ferric species, $\mathrm{F}_{8} \mathrm{Fe}^{\mathrm{lll}} \mathrm{SbF}_{6}$, coordinated to $\mathrm{X}$, a ligand which may be imidazole, water, TFA, etc. The ${ }^{2} \mathrm{H}-\mathrm{NMR}$ signature of the isoporphyrin complex matches the ${ }^{2} \mathrm{H}-\mathrm{NMR}$ acquired at $-80^{\circ} \mathrm{C}$ in dichloromethane for the iron(III) meso-chloro-isoporphyrin reported by Fujii and co-workers. ${ }^{11}$ It is of note that the signal is very weak and four peaks for the isoporphyrin complex due to the meso functionality causing the deuterated pyrrole signals to be inequivalent. Upon, addition of 
4-methoxyphenol the peaks coalesce into one intense peak because now the imidazole has been transferred to the phenol substrate and one ferric product has been formed, wherein the deuterated pyrrole peaks are now all equivalent.

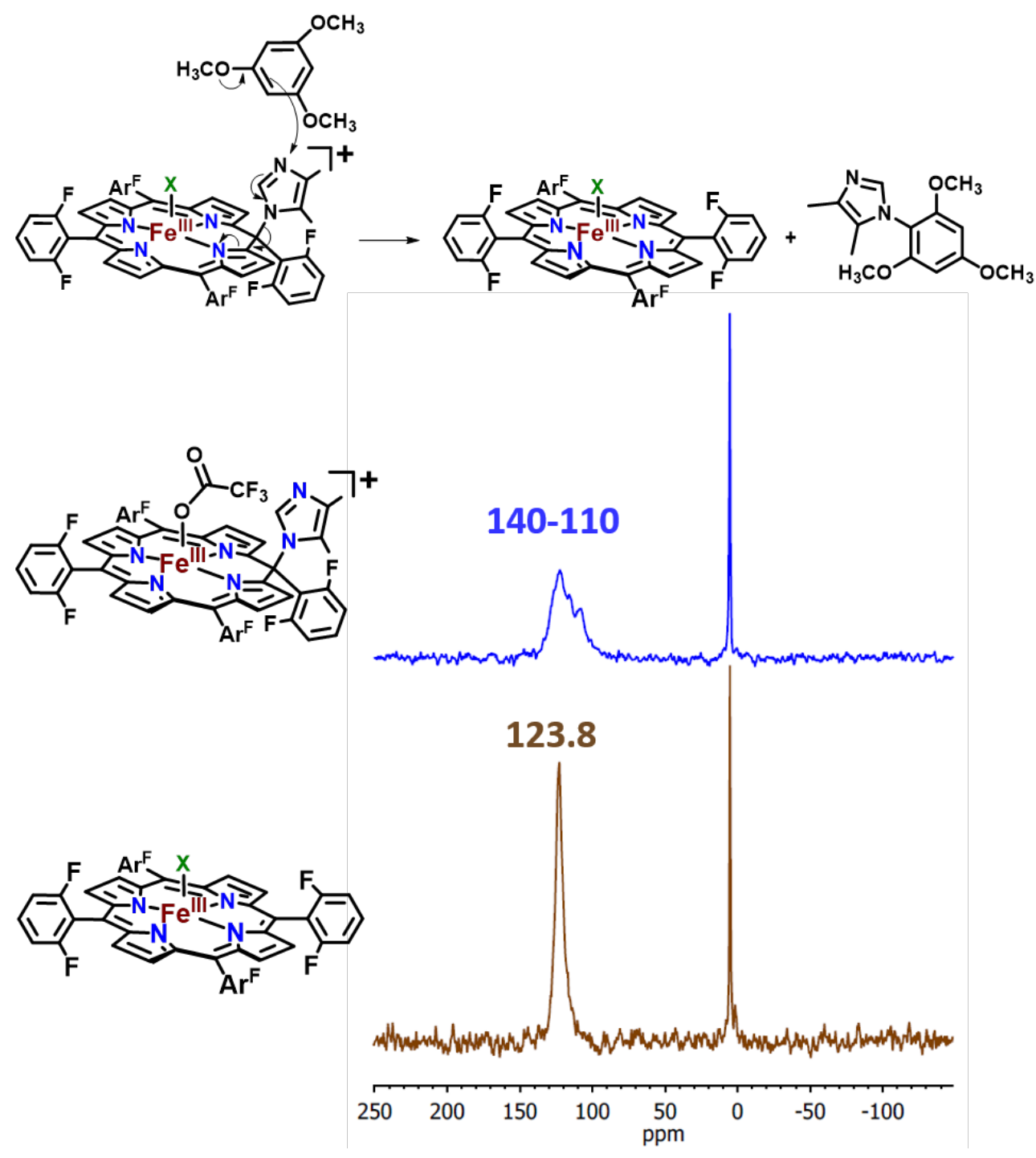

Figure S17. ${ }^{2} \mathrm{H}-\mathrm{NMR}$ spectra (wherein the pyrroles are deuterated, the starting material employed was $d_{8}-\mathrm{F}_{8} \mathrm{Fe}^{\text {llI }} \mathrm{SbF}_{6}$ ) following the addition of 50 equiv. 1,3,5-trimethoxybenzene to $5 \mathrm{mM}$ iron(III) meso-4,5-dimethylimidazole-isopoprphyrin in DCM at $-90^{\circ} \mathrm{C}$. Spectra were calibrated to residual deuterated $\mathrm{DCM}$ at $5.32 \mathrm{ppm}$. The resulting ${ }^{2} \mathrm{H}-\mathrm{NMR}$ spectra in brown is thought to be the starting material ferric species, $\mathrm{F}_{8} \mathrm{Fe}^{\mathrm{Ill}} \mathrm{SbF}_{6}$, coordinated to $\mathrm{X}$, a ligand which may be imidazole, water, TFA, etc. The ${ }^{2} \mathrm{H}-\mathrm{NMR}$ signature of the isoporphyrin complex matches the ${ }^{2} \mathrm{H}-\mathrm{NMR}$ acquired at $-80^{\circ} \mathrm{C}$ in dichloromethane for the iron(III) meso-chloro-isoporphyrin reported by Fujii and co-workers. ${ }^{11}$ It is of note that the signal is very weak and four peaks for the isoporphyrin complex due to the meso functionality causing the deuterated pyrrole signals to be inequivalent. Upon, addition of 1,3,5-trimethoxyphenol the peaks coalesce into one intense peak because now the imidazole has been transferred to the phenol substrate and one ferric product has been 
formed, wherein the deuterated pyrrole peaks are now all equivalent.

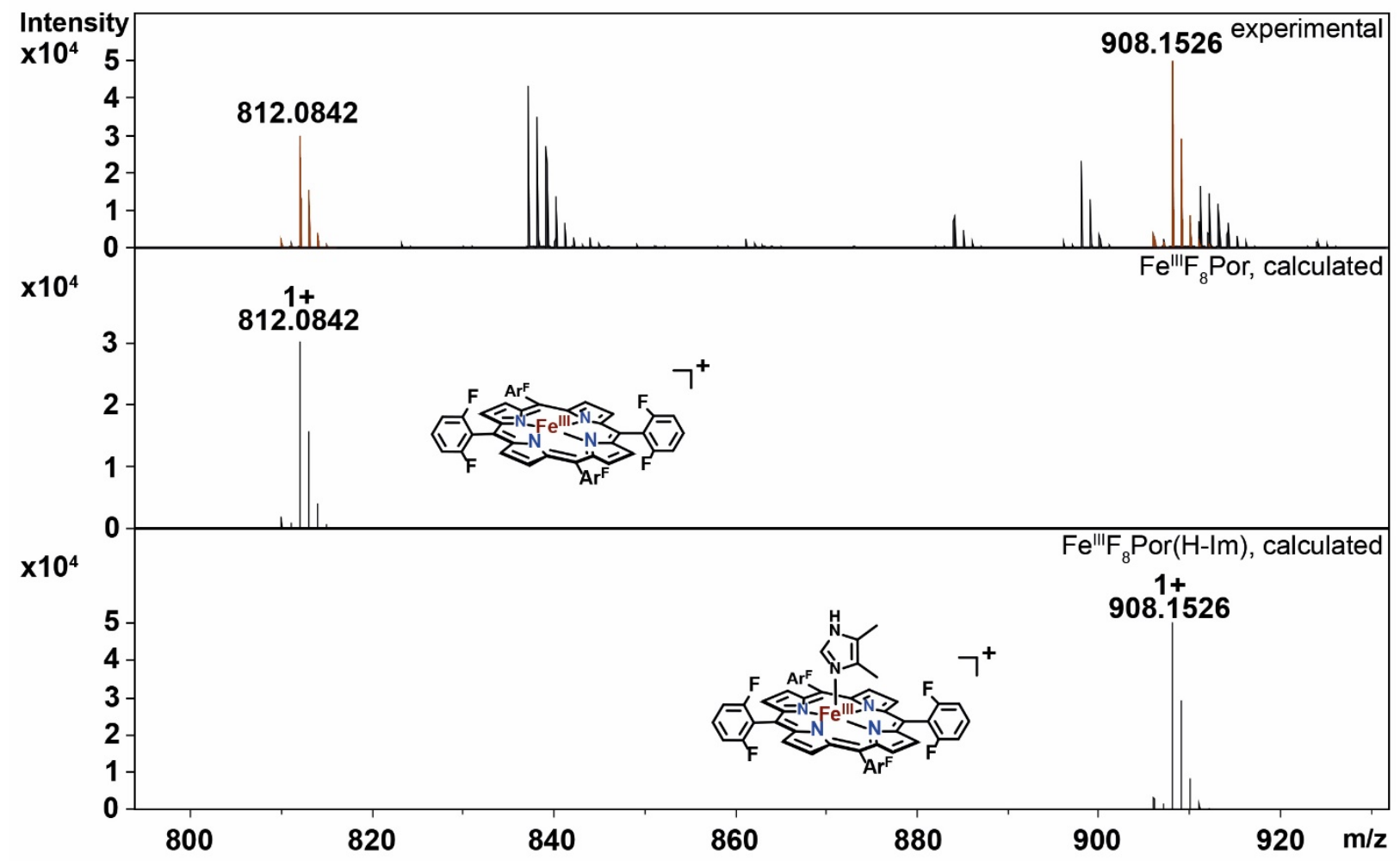

Figure S18. Cryo-ESI-MS spectra depicting the inorganic products detected following the addition of 50 equiv. 4-methoxyphenol to iron(III) meso-4,5-dimethylimidazoleisopoprphyrin in DCM at $-90^{\circ} \mathrm{C}$. Simulated spectra are shown below that support complex identification. 


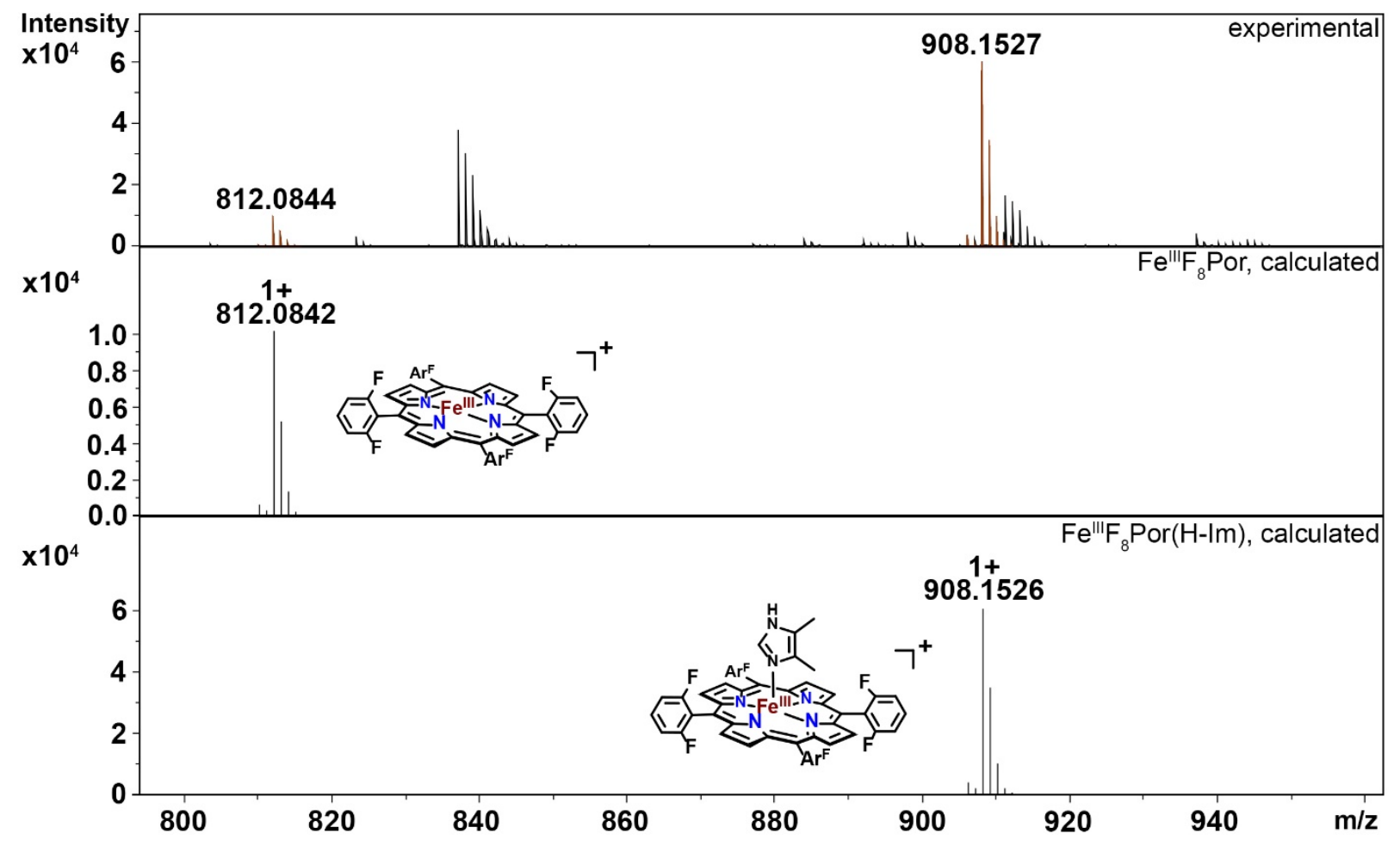

Figure S19. Cryo-ESI-MS spectra depicting the inorganic products detected following the addition of 50 equiv. 1,3,5-trimethoxybenzene to iron(III) meso-4,5-dimethylimidazoleisopoprphyrin in DCM at $-90^{\circ} \mathrm{C}$. Simulated spectra are shown below that support complex identification. 


\section{References}

(1) Davidson, V. L. Protein-Derived Cofactors Revisited: Empowering Amino Acid Residues with New Functions. Biochemistry 2018, 57, 3115-3125.

(2) Davidson, V. L. Protein-Derived Cofactors. Expanding the Scope of PostTranslational Modifications. Biochemistry 2007, 46, 5283-5292.

(3) Ghiladi, R. A.; Knudsen, G. M.; Medzihradszky, K. F.; Ortiz De Montellano, P. R. The Met-Tyr-Trp Cross-Link in Mycobacterium Tuberculosis Catalase-Peroxidase (KatG): Autocatalytic Formation and Effect on Enzyme Catalysis and Spectroscopic Properties. J. Biol. Chem. 2005, 280, 22651-22663.

(4) Ghiladi, R. A.; Medzihradszky, K. F.; Ortiz de Montellano, P. R. Role of the Met-Tyr-Trp Cross-Link in Mycobacterium Tuberculosis Catalase-Peroxidase (KatG) As Revealed by KatG(M255I) ${ }^{\dagger}$. Biochemistry 2005, 44, 15093-15105.

(5) Bertrand, T.; Eady, N. A. J.; Jones, J. N.; Jesmin; Nagy, J. M.; Jamart-Grégoire, B.; Raven, E. L.; Brown, K. A. Crystal Structure of Mycobacterium Tuberculosis Catalase-Peroxidase. J. Biol. Chem. 2004, 279, 38991-38999.

(6) Schrodinger LLC. The PyMOL Molecular Graphics System, Version 1.8. 2015.

(7) Cedervall, P.; Hooper, A. B.; Wilmot, C. M. Structural Studies of Hydroxylamine Oxidoreductase Reveal a Unique Heme Cofactor and a Previously Unidentified Interaction Partner. Biochemistry 2013, 52, 6211-6218.

(8) Pearson, A. R.; Elmore, B. O.; Yang, C.; Ferrara, J. D.; Hooper, A. B.; Wilmot, C. M. The Crystal Structure of Cytochrome P460 of Nitrosomonas Europaea Reveals a Novel Cytochrome Fold and Heme-Protein Cross-Link. Biochemistry 2007, 46, 8340-8349.

(9) Bhuyan, J. Metalloisoporphyrins: From Synthesis to Applications. Dalton Trans. 2015, 44, 15742-15756.

(10) Gold, A.; Ivey, W.; Toney, G. E.; Sangaiah, R. Ferric Isoporphyrins from Hydroperoxide Oxidation of (Tetraphenylporphinato) Iron (III) Complexes. Inorg. Chem. 1984, 23, 2932-2935.

(11) Cong, Z.; Kurahashi, T.; Fujii, H. Formation of Iron(III) Meso-Chloro-Isoporphyrin as a Reactive Chlorinating Agent from Oxoiron(IV) Porphyrin m-Cation Radical. J. Am. Chem. Soc. 2012, 134, 4469-4472.

(12) Abhilash, G. J.; Bhuyan, J.; Singh, P.; Maji, S.; Pal, K.; Sarkar, S. $\cdot \mathrm{NO}_{2}-$ Mediated Meso -Hydroxylation of Iron(III) Porphyrin. Inorg. Chem. 2009, 48, 1790-1792.

(13) Garcia-Bosch, I.; Sharma, S. K.; Karlin, K. D. A Selective Stepwise Heme Oxygenase Model System: An Iron(IV)-Oxo Porphyrin m-Cation Radical Leads to a Verdoheme-Type Compound via an Isoporphyrin Intermediate. J. Am. Chem. Soc. 2013, 135, 16248-16251. 